أثز برنامج علاجي قائم على فنيات سيكولوجية الحياة الايجابية في خفض سلوك الانسحاب الاجتماعي لدى عينة من طلاب

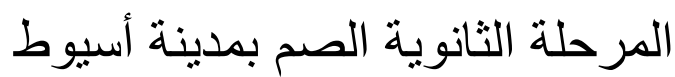

\title{
D) ol
}

أ.د/عماد أحمد حسن علي أ.م.د/عبد الله محمد عبد الظاهر

أستاذ الصحة النفسية المساعـد-

كلية التربية - جامعة أسيوط

أستاذ علم النفس التزبوي

ووكيل الكلية لشئون خدمة المجتمع

وتنمية البيئة كلية التربية - جامعة أسيوط

\section{أ/ وليد محمد محمد سبد صساح \\ باحث شئون تعليم - مركز تطوير التعليم الجامعي \\ - الإدارة العامة - جامعة أسيوط}

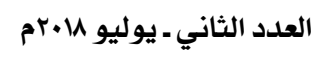


هدفت الدراسة إلي التعرف على أثز برنامج علاجي قائم على فنيات سيكولوجية الحياة الايجابية في خفض سلوك الانسحاب الاجتماعي تجاه الأشخاص السامعين وأثره في تحسين تقدير الذات لدى المراهقين الصم كلياً ،وقد اثتتملت عينة الدراسة الاستطلاعية

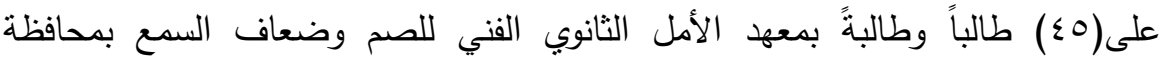

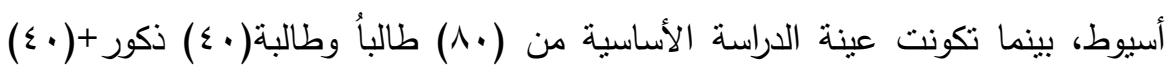
إناث تم اختيارهم بطريقة مقصودة من متوسطي الذكاء وذوي المستوي الاجتماعي

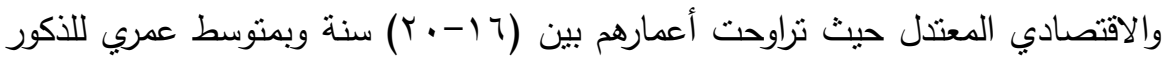

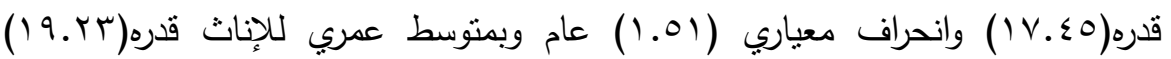

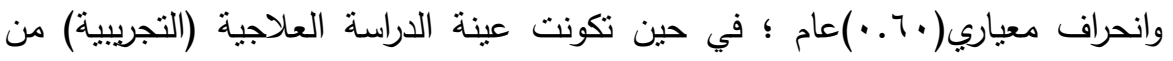

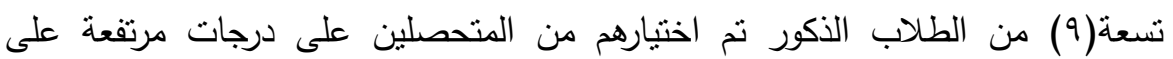

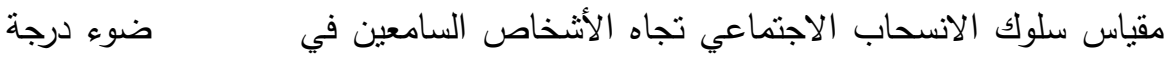

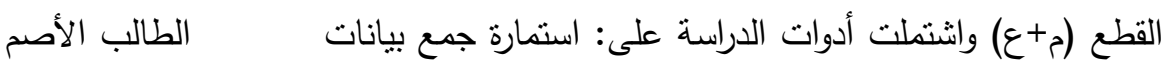
الثخصية والاجتماعية (إعداد الباحث)،ومقياس سلوك الإنس الأسحاب الاجتماعي للمراهق

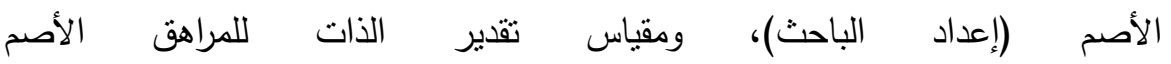
(إعداد/إيمان كاثف)،والبرنامج العلاجي القائم على فنيات سيكولوجية الحياة الايجابية

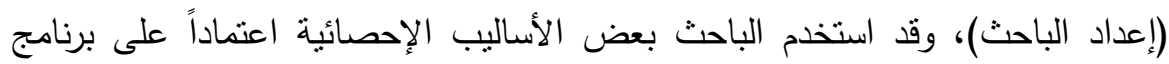
عند معالجة فروض الدراسة.

$$
\text { وقد أسفرت الاراسة عن :- }
$$

• وجود فروق ذات دلالة إحصائية بين متوسطي درجات المراهقين الصم كلياً بين الذكور

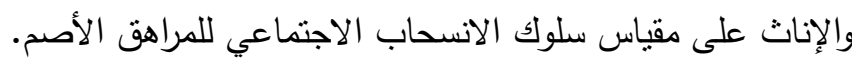

• وجود فروق ذات دلالة إحصائية بين متوسطي درجات المجموعة التجريبية في القياسين

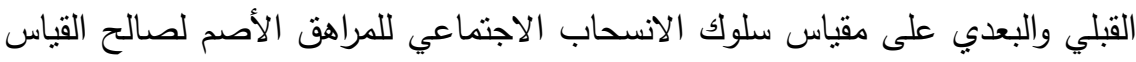




\section{Abstract}

The study aimed to identify the effect of a therapeutic program based on techniques of positive psychology in reducing social withdrawal behavior of deaf adolescence towards hearing people. The explotary sample of the study included $(\leqslant 0)$ forty-five deaf students in Al-Amal technical secondary institute for the deaf and hearingimpaired at Assiut city, while the main sample of the study consisted of( $(\bullet)$ eighty male and female deaf students $\left(\varepsilon_{\cdot}\right)$ males $+\left(\varepsilon_{\cdot}\right)$ females who were chosen in a deliberate manner from those with moderate to high "IQ scores" and also with moderate socioeconomic levels. The age of the main sample ranged from $\left(1 Y-r_{\cdot}\right)$ years: mean of $(1 \mathrm{~V} . \leqslant 0)$ and standard deviation (1.01) years for males, and mean of (19.r 1 ) and standard deviation $(\cdot .7 \cdot)$ years for females. The therapeutic study sample consists of (9) male students who were selected according to their high scores on the measure of social withdrawal behavior towards hearing people in the light of the cut-degree (mean + standard deviation). Tools of the study included the following: Personal and social data collection form of deaf students (prepared by the researcher), social withdrawal behavior scale of the deaf adolescent (SWS-DA) (prepared by the researcher), and the suggested program based on the therapeutic techniques of positive psychology (prepared by the researcher).The researcher used some statistical methods according to (SPSS) program when addressing hypotheses of the study.

\section{The study found the following results:}

- There were statistically significant differences at the average scores of deaf adolescents between males and females on social withdrawal behavior scale for deaf adolescent (SWS-DA) in favor of females.

- There were statistically significant differences at the mean rank scores of the therapeutic group in pre-post test on social withdrawal behavior scale for deaf adolescent(SWS-DA) for the benefit of pre-measurement. 
يمكن اعتبار فئة الأفراد ذوى الاحتياجات التربوية السمعية الخاصة من الصم

ظاهرة لها خصوصيتها مقارنة بمن سواهم من أفراد الفئات الأخرى، وقد تكون الإعاقة السمعية أحد هذه العوامل ذات التأثير السلبي أو الايجابي علي مشاعر وانفعالات الأصم؛ فالأصم يجد صعوبة في وصف مشاعره تجاه الآخرين وتجاه نفسه ، لأن الإعاقة تخلق

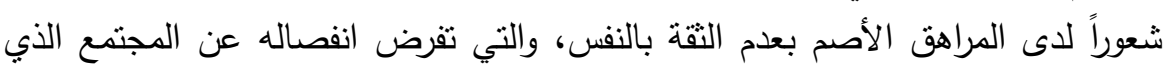

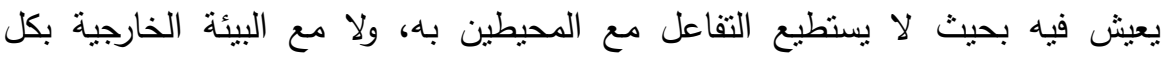

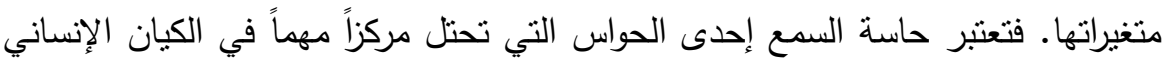

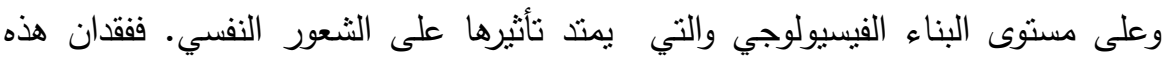

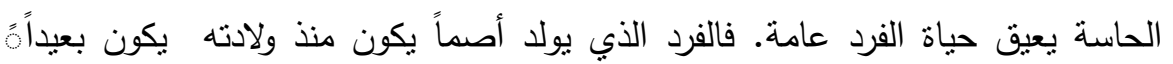
ومنعزلاً عن الوسط الذي يعيش فيه. إذا تحرمه إعاقته من الاكتساب الطبيعي للمنبهات

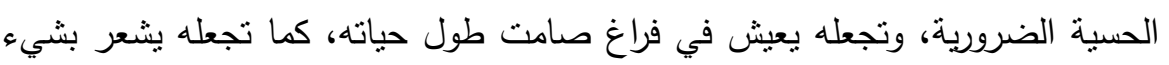

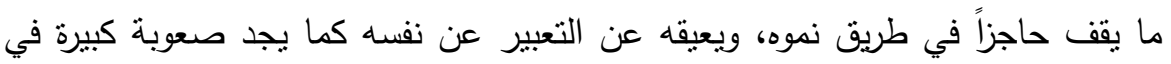
ربط علاقة بين ذاته والمحيطون به، وكل هذا قد يؤدي به إلى التهميش الذي يبدأ منذ

الطفولة المبكرة.

تمثل إحدى مؤشرات حضارة الأمم في مدى عنايتها بتربية أبنائها بمختلف فئاتهم ويشمل ذلك ما تقدمه من عناية واهتمام للطلاب ذوي الحاجات الخاصة، لأن إهمال هذه ومن هنا الفئة يؤدي إلى تعرضهم للمزيد من المشكلات التي تضاعف إعاقتهم (عادل) يلزم التدخل العلاجي لمواجهة المشكلات التي نترنب لتهري على الإعاقة

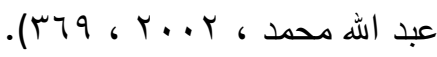

تظهر المشكلات السلوكية والانفعالية بشكل عام لاى المراهق الأصم في أثكال السلوكيات الخارجية والداخلية، فتكون السلوكيات الخارجية موجهة نحو الآخرين كالعدوان والسب والسرقة والعنف والتمرد والانحراف، بينما تكون السلوكيات الداخلية موجهة بصورة

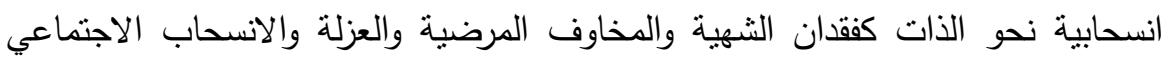

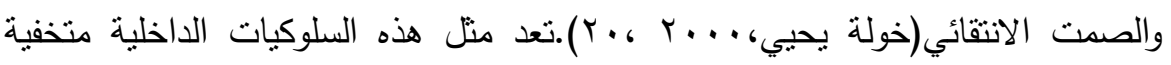

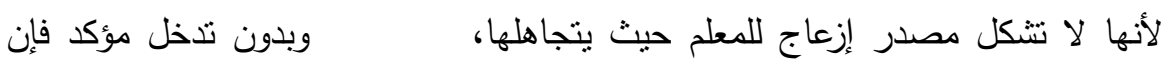

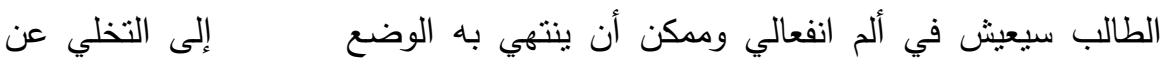

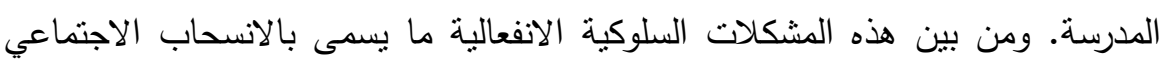
والذي يصنف ضمن صعوبات التعليم الاجتماعي والانفعالي (سامي ملحم ، ع. . . ؟، Y ( ). يعبر سلوك الانسحاب الاجتماعي عن طبيعة العلاقة الاجتماعية المحدودة للمراهق

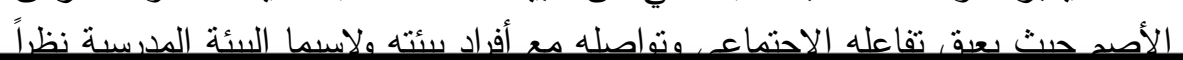




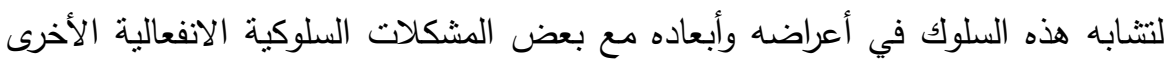

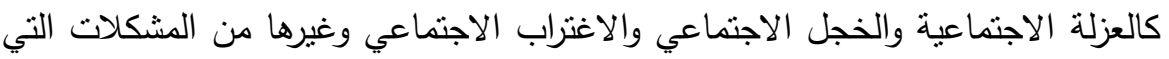

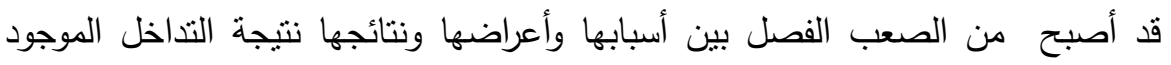

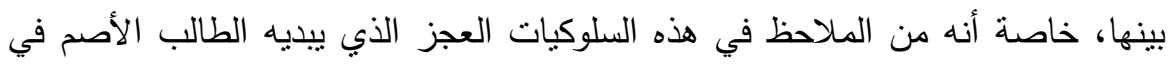
ومعلميه السامعين.

بناء العلاقات الاجتماعية مع غيره من أقرانه تعتبر حاسة السمع إحدى الحواس التي تحتل مركزاً مهماً في الكيان الإنساني

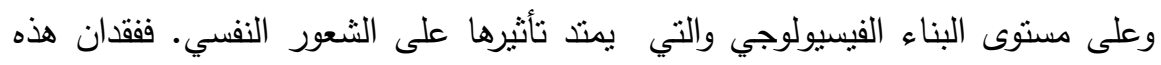

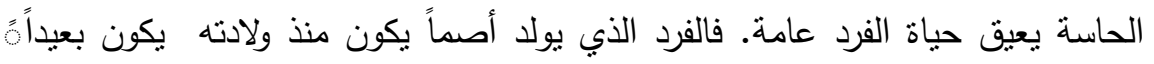

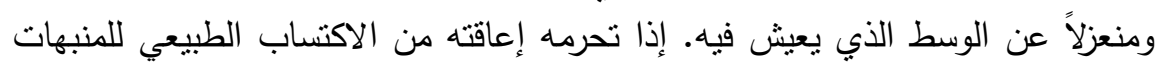

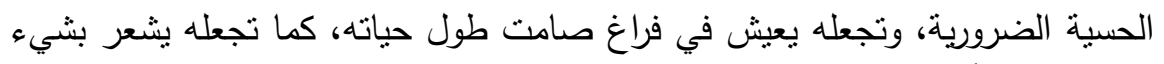

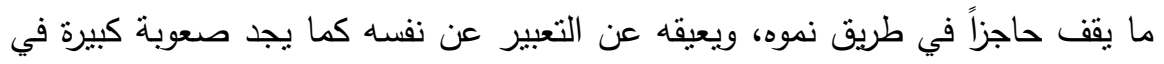

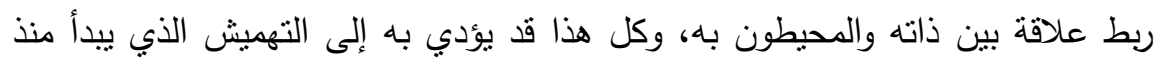

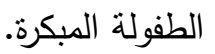

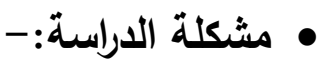

ظهرت فكرة هذه الدراسة من خلال المتابعة لسلوك وتصرفات الطلاب الملتحقين

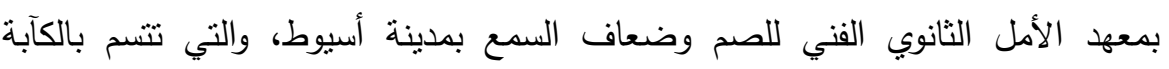

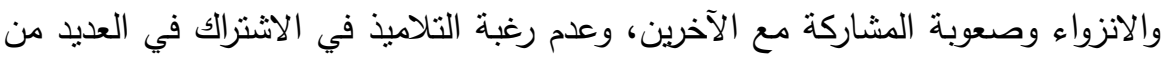

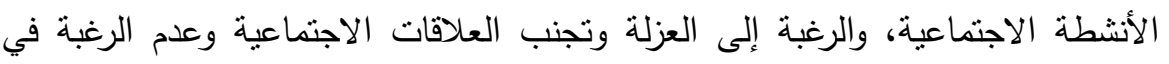

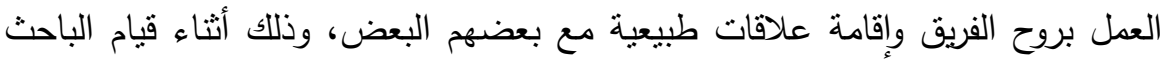

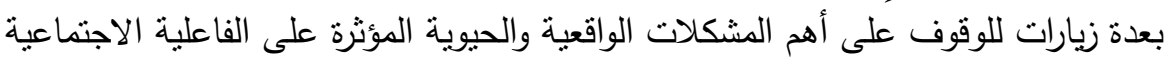

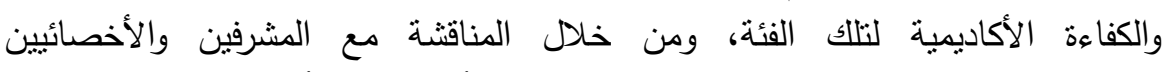

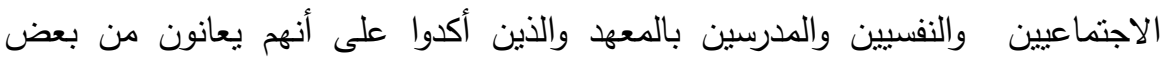

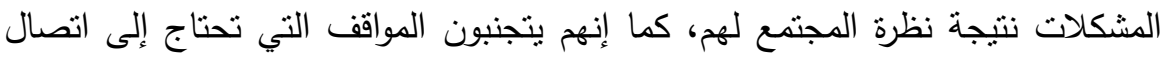

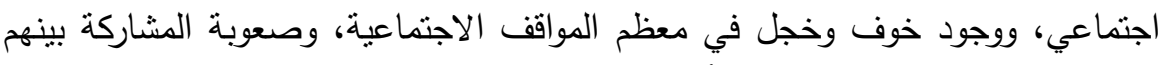

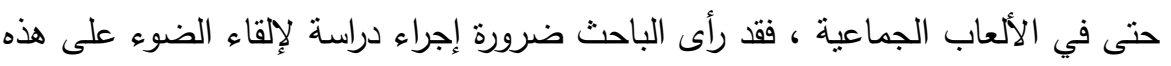

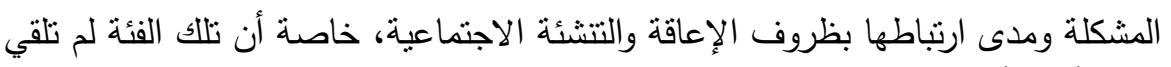

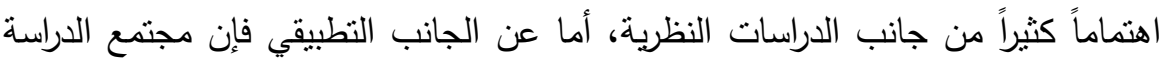

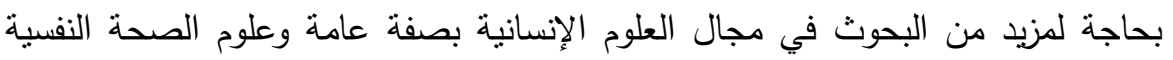

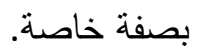

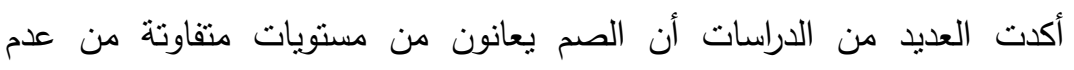

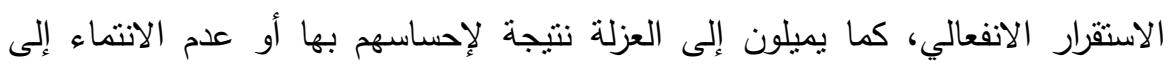

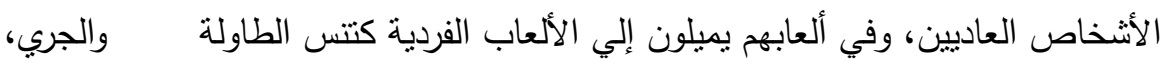


لذا فالإعاقة السمعية تترك تأثثرات كبيرة على قدرتهم على مخالطة الآخرين، يفضل الانزواء النفسي والعيش في عزلة، فهو يتسم بالعجز عن إقامة علاقات اجتماعية

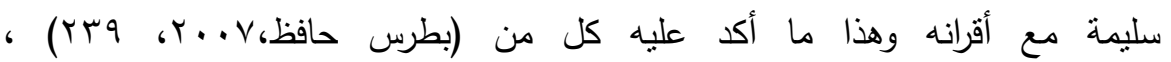
.(Lokanadha, r...,, (L))

أكدت نتائج العديد من الدراسات ذات التوجهات التربوية الحديثة على أن تدخل التدريب في عمر مبكر للصم يلعب دورًا جيدًا في تأهيلهم الاجتماعي وتحسين قدراتهم التواصلية بشكل يساعد على اندماجهم في البيئة مما يمنل اللبنة الأولى في بناء علافات اجتماعية ناجحة وتكوين صداقات مع الأقران ، وتعلم المهارات الحياتية اللازمة لهذه

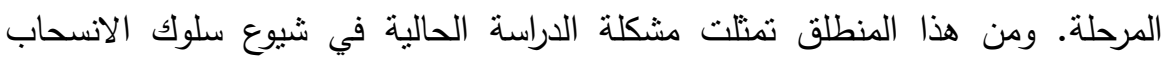

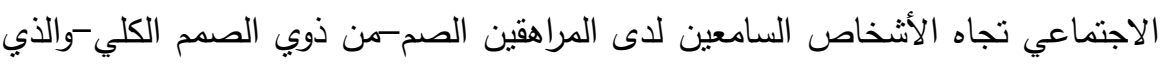

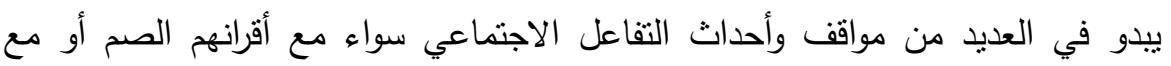
أقرانهم العاديين، مما يستلزم وجود البرامج العلاجية المناسبة للتخفيف من طبيعة هذاء مناء السلوك الانسحابي عن طريق برامج وإجراءات وفنيات إدارة الذات.

وإذا كان الهدف الأسمى للتربية الخاصة يتمثل في تعديل سلوك الصم بغرض الصن التكيف مع متطلبات البيئة الاجتماعية، وتذليل الصعوبات أمام تلك الفئة قصد مساعدة فئية أنفسهم للتخلص إلى حد بعيد من سلوك الانسحاب الاجنماعي وانطلاقًًا من هذا نطرح مشكلة الدراسة الحالية في سؤال رئيسي هو :

"ما أثر برنامج علاجي قائم على فنيات سيكولوجية الحياة الايجابية في خفض الأل

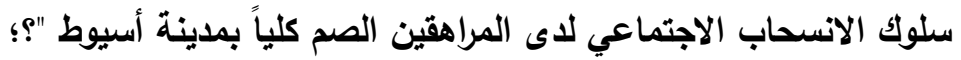
وتتبع من المشكلة الرئيسية للاراسة بعض الأسئلة التي تهدف الاراسة إلى الوصول لأجابتها وهي-: 1- ما نسبة انتسار سلوك الانسحاب الاجتماعي في عينة الدراسة الأساسية من المراهقين

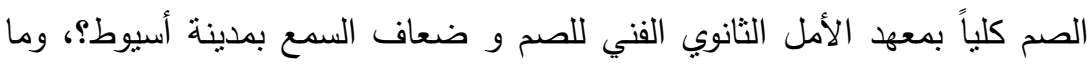
الفرق بين كَل من(الذكور والإناث) في مستوى سلوك الانسحاب الاجتماعي في لإني

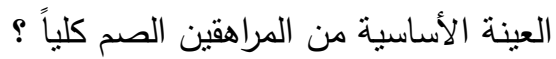
ץ- هل تساعد الدراسة على إعداد برنامج علاجي قائم على فنيات سيكولوجية الحياة الايجابية يساعد في خفض سلوك الانسحاب الاجتماعي لاي المراهقين الصم كلياً ؟ • أهداف الدراسة: - أن

في ضوء تعيين مشكلة الاراسة يمكن صياغة الأهداف التي تسعى الدراسة لتحقيقها في النقاط الآتية: 
1- تحديد نسبة انتشار سلوك الانسحاب الاجتماعي تجاه الأشخاص السامعين في عينة

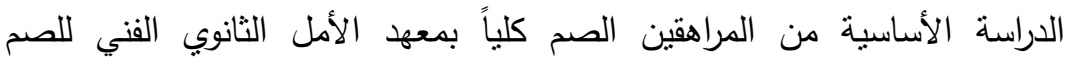
وضعاف السمع بمدينة أسيوط، مع التعرف على النى الاختلاف في مدى انتشاره

$$
\text { باختلاف النوع(ذكور /إناث). }
$$

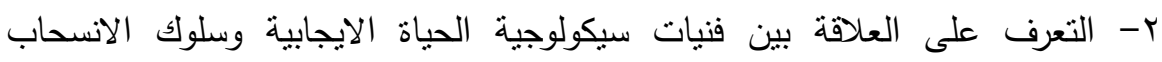
الاجتماعي تجاه الأثخاص السامعين لاى عينة علاجية من المراهقين الصم كلياً.

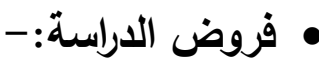

1- توجد فروق ذات دلالة إحصائية بين متوسطي درجات العينة الأساسية من المراهقين

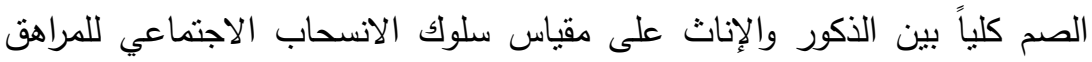

r-يوجد فرق ذو دلالة إحصائية بين منوسطي رتب درجات العينة العلاجية في القياسين

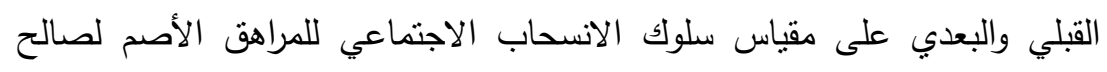

$$
\text { القياس القبلي. }
$$

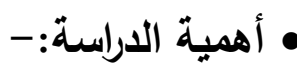

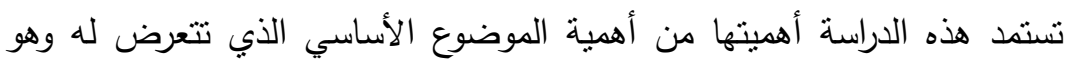

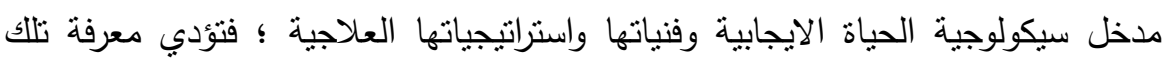

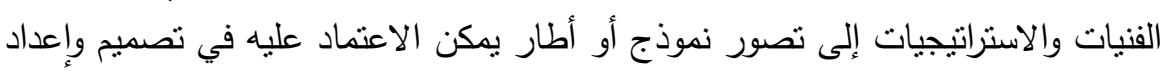

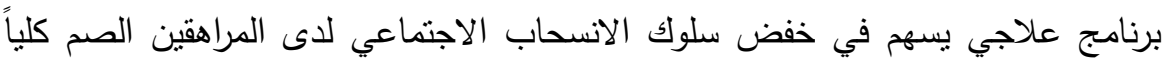

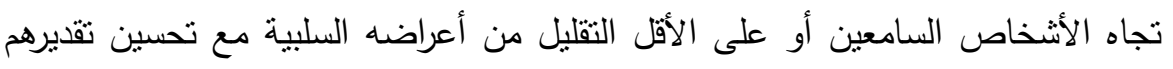

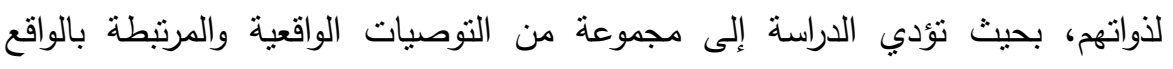

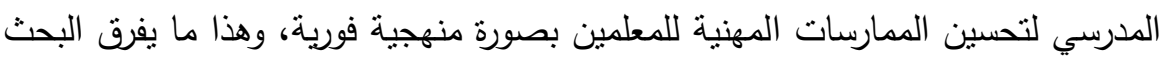

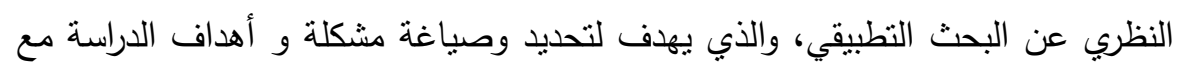

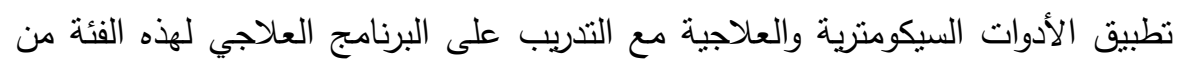

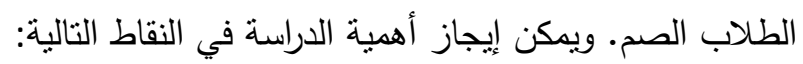

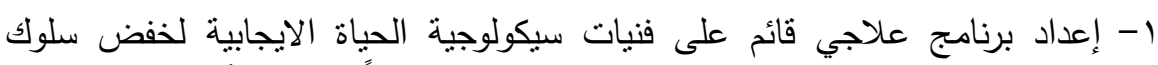

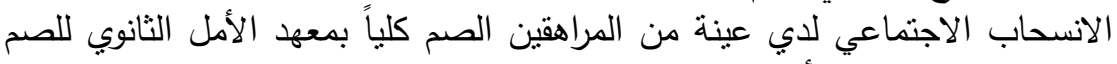

$$
\text { وضعاف السمع بمدينة أسبوط. }
$$

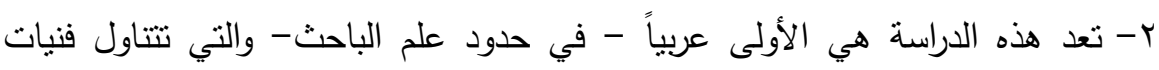
سيكولوجية الحياة الايجابية بشكل الاولى عام ولدي في ذوردي الإعاقة السمعية على وجه

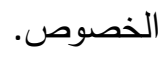


r- تعد هذه الدراسة هي الأولى التي يتم من خلالها تطبيق جلسات برنامج علاجي الإبي

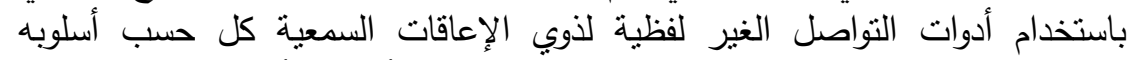
الخاص في عملية التواصل (سواء من خلال لغة الإثشارة أو عبر أبجدية الأصابع).

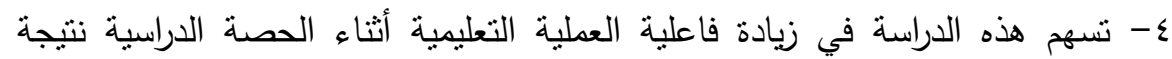

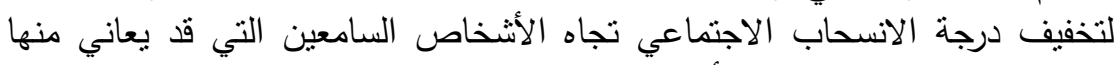
المراهقين الصم بحيث يجعلهم أكثر ومقدرة على الوفاء بمنطاه الأبات العات العمل التزبوي.

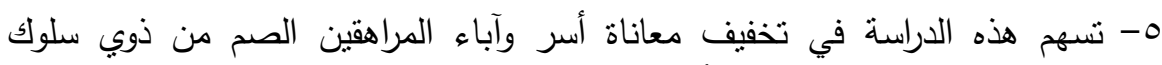

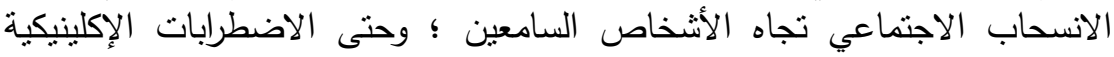

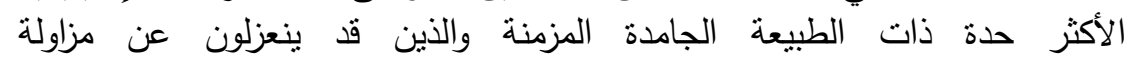

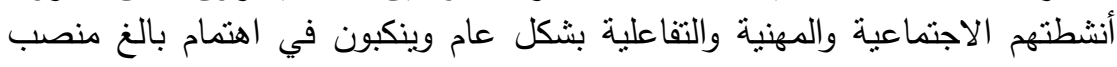

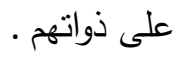

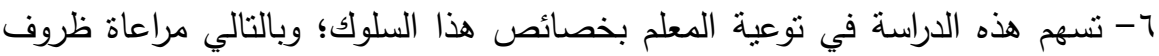

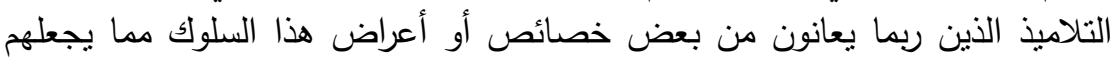
أكثر قدرة على تحفيز مشاركة هذه الفئة من الطلاب في العند الأنشطة الدراسية الجماعية.

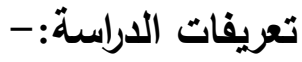

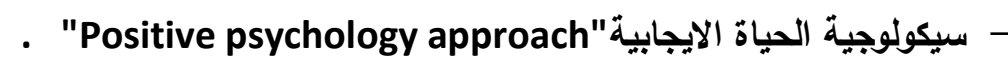

تُعرف "سيكولوجية الحياة الايجابية" بأنها" الدراسة الموضوعية للخصال الإنية الإنيجابية

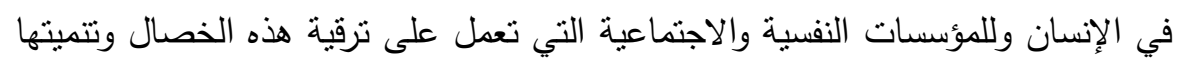

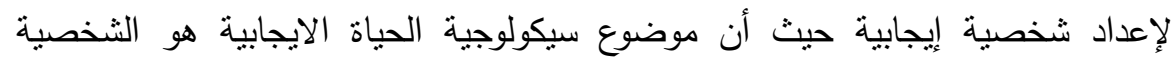

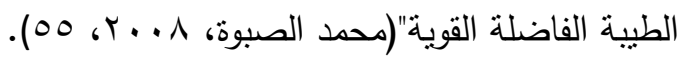

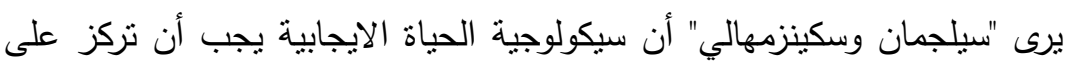

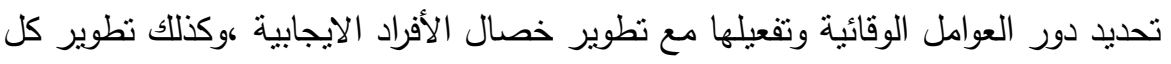

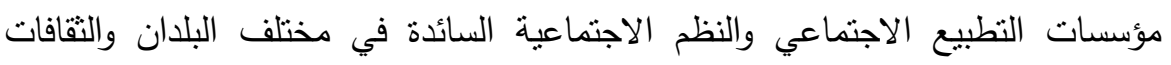

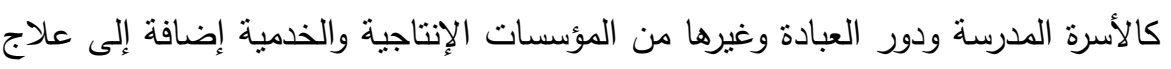

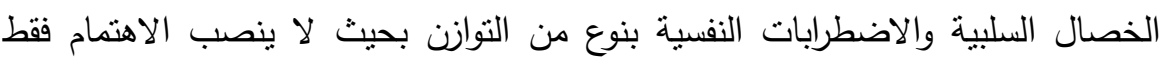

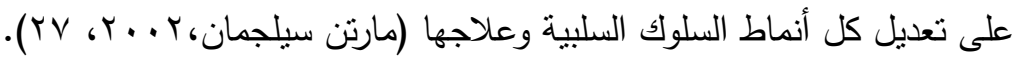

"Social Withdrawal Behavior " سلوك الانسحاب الاجتماعي يعرف "سلوك الانسحاب الاجتماعي" بكونه "الميل إلى تجنب التفاعل الاجتماعي،

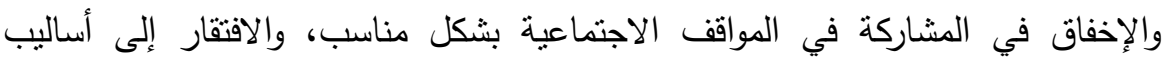

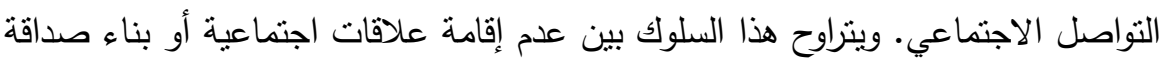

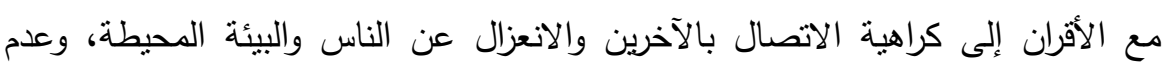


الاكتراث بما يحدث في البيئة المحيطة. وقد يبدأ في سنوات ما قبل الدراسة، ويستمر

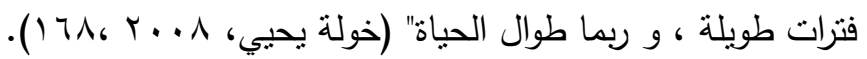

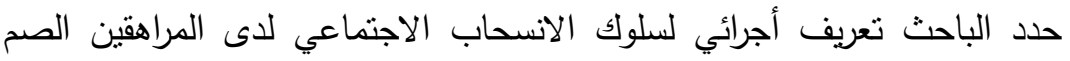

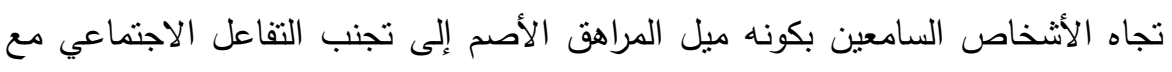

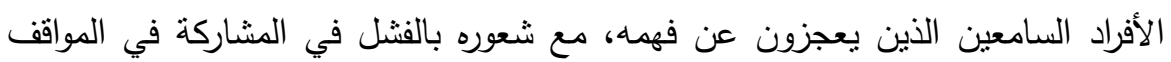

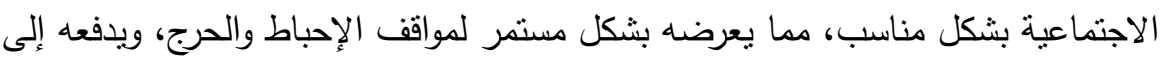

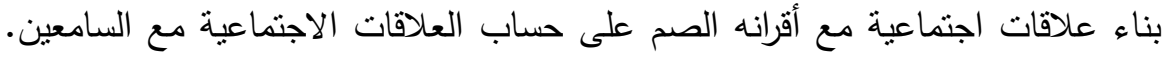

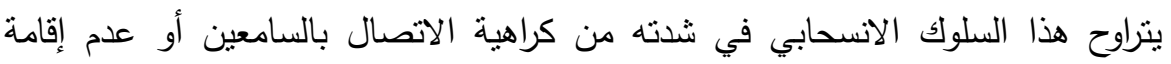

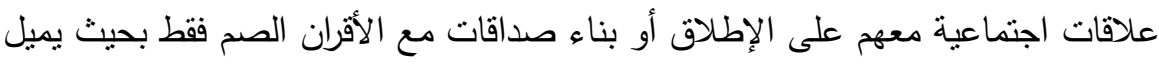
للانعزال عن الناس، وعن البيئة المحيطة المحبطة، وعدم الاكتراث بما يحدث فيها.

"Entirely-deaf Adolescent"المراهق الأصم كلياً -

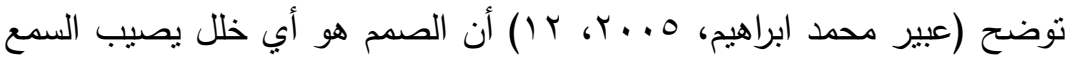

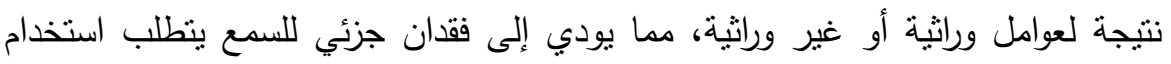

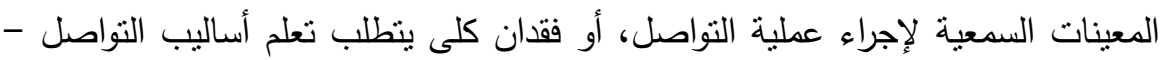

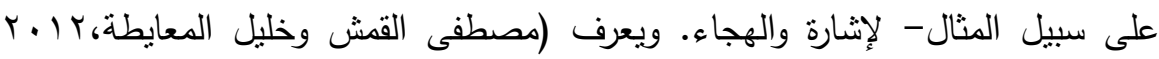

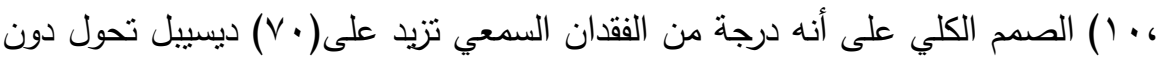

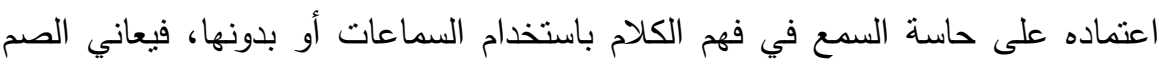

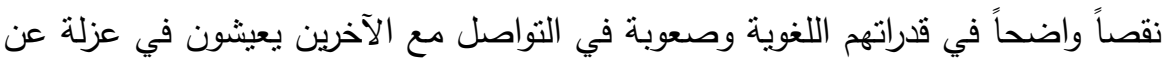

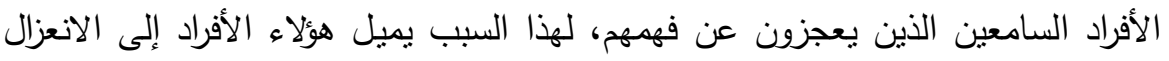

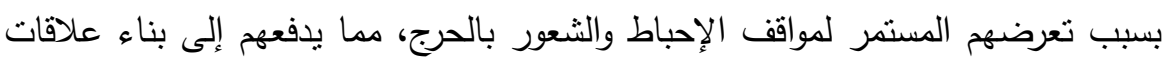

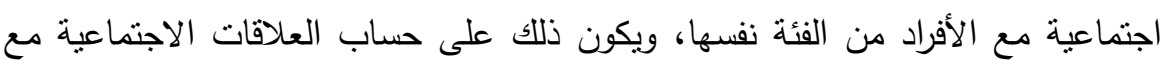

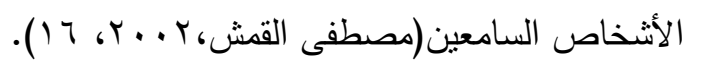

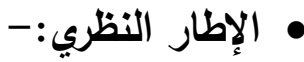

يقدم الباحث في هذه الدراسة إطار عمل للفنيات التربوية الايجابية للممارسين

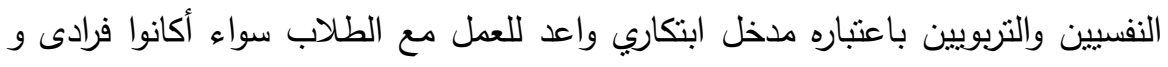

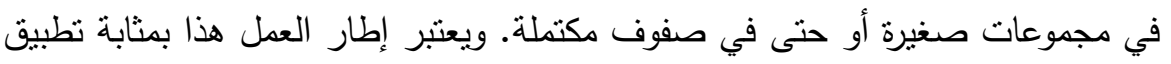
للمبادئ الجوهرية والتوصيات الخاصة بسيكولوجية الحياة الايجابية. ومن ثم يتمثل التركيز 
الأساسي لهذه الدراسة في كيفية المساعدة على تسهيل الحياة المنتعشة التي تحسن جودة

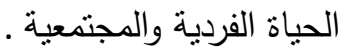

بعثبر "مارتن سليجمان" رائد مدرسة السيكولوجية الايجابية، فيعنقد أن الحياة الهانئة

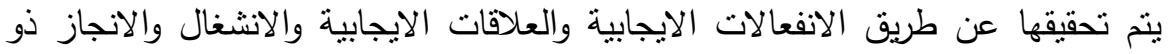

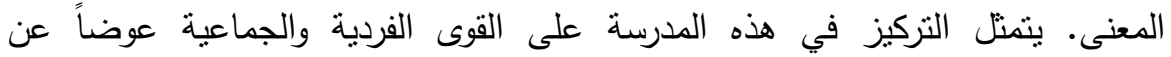

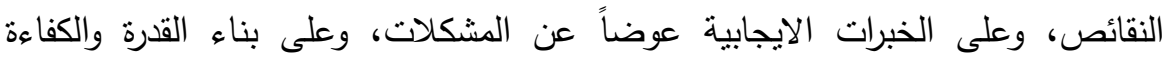

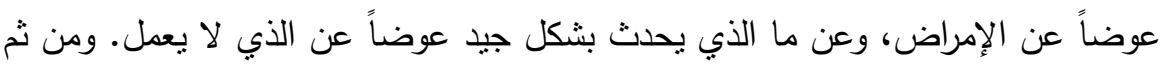

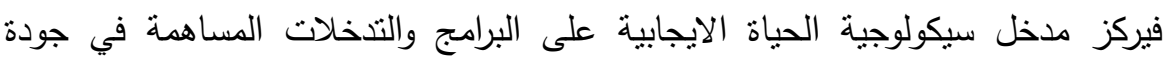

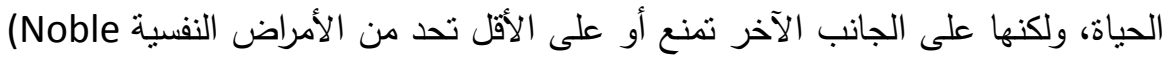
\& McGrath, $Y$...人, 119).

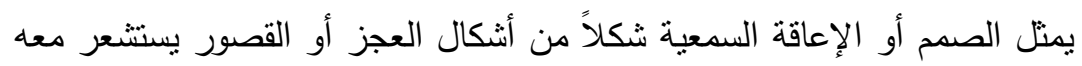

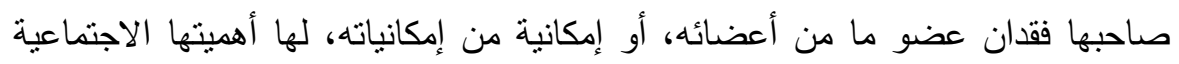

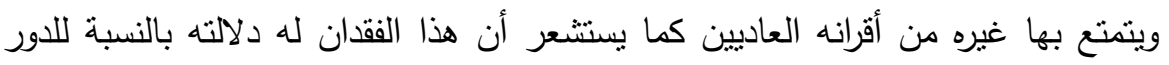

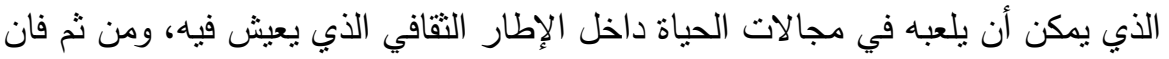

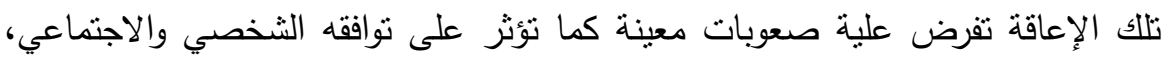

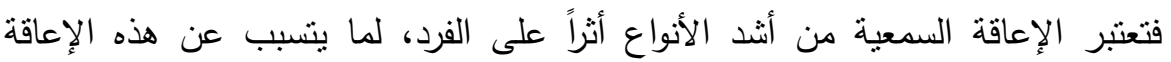

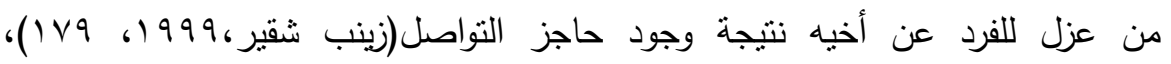

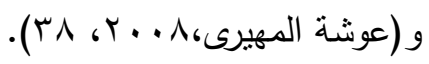

يؤكد (ع . . Clonan et al., على مدخل سيكولوجية الحياة الايجابية النطبيقي

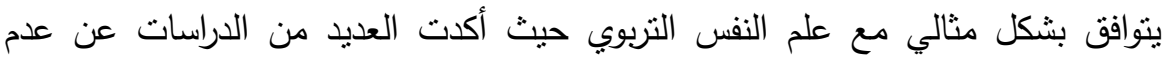

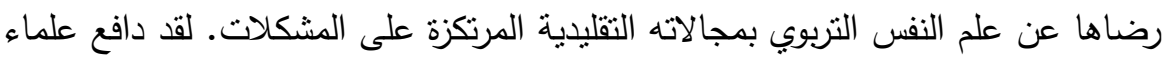

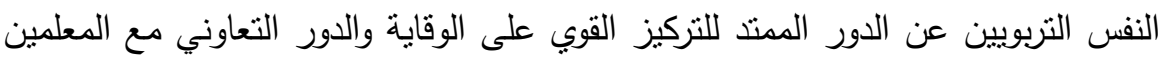

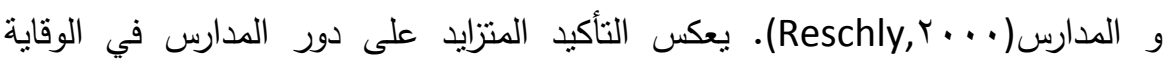

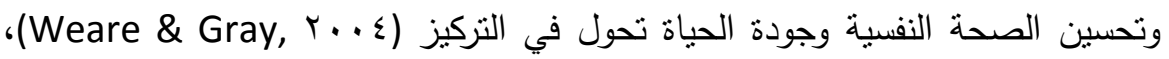

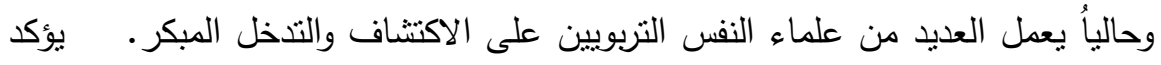
(Reschly \& Ysseldyke, 1999)

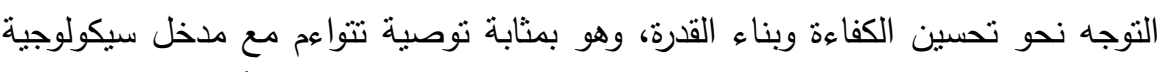

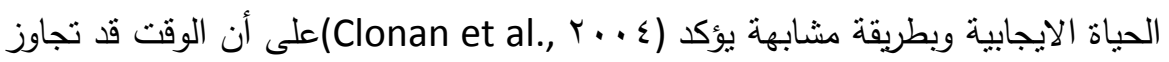
حالياً علم النفس التربوي الايجابي. - قواعد سيكولوجية الحياة الايجابية التريوية: - 
يعمل علماء سيكولوجية الحياة الايجابية على تبني وتطبيق القواعد الخمسة لجودة الحياة المدرسية ؛ فيتم تدعيم قواعد سيكولوجية الحياة الايجابية التربوية عن طريق تتظيم الدلائل البحثية تحت تلك القواعد الخمسة يمكن تشكيل إطار عمل مفيد وشامل لتسهيل عمل علماء النفس التربويين في تطوير جودة الحياة الشخصية والجماعية والمدرسية بحيث

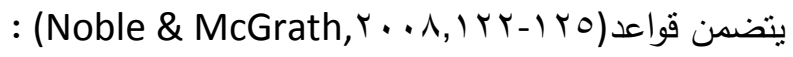
1- الكفاءة الاجتماعية والانفعالية؛ والذي يتضمن أبعاد :مهارات مقاومة الضغوط، ومهارات التمييز الانفعالي، ومهارات الانجاز الثخصي.

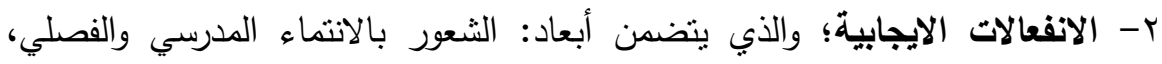

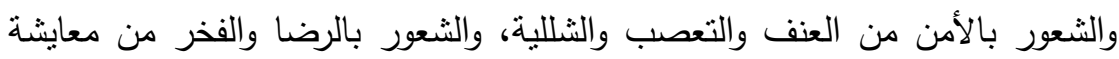
والاحتفال بالنجاح، والثعور بالإثارة والمتعة عن طريق المشاركة في أنشطة ترفيهية وحفلات خاصة والعاب تربوية، والثعور بالتفاؤل من النجاح المدرسي.

r- العلاقات الايجابية ؛والذي يتضمن أبعاد: العلاقات الايجابية بين الأقران، وبين التلامبذ والمعلمين والتي تجعل التلاميذ يشعرون بالانتماء والتواصل مع معايشة التعابه

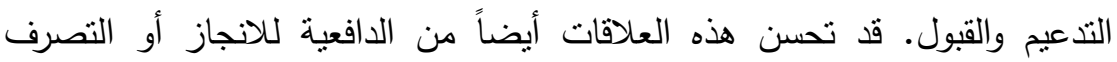
بالتوافق مع نقافة المدرسة الاجتماعية.

ع- الإدماج عن طريق القوى الأتية؛ والذي يتضمن أبعاد: جودة الحياة والسلوك

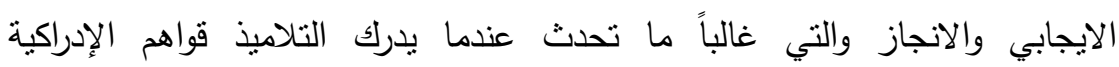
والثخصية مع امتلاكهم فرص لنظوير تلك القوى داخل المدرسة. يدعم تباين المقررات

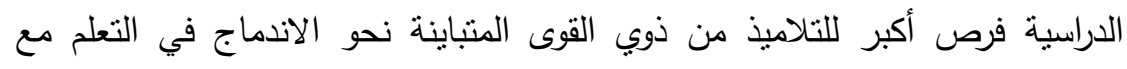
الانجاز بطريقة صحيحة. 0- الشعور بالمعنى والهدف؛ والذي يتضمن أبعاد: جودة الحياة والانجاز والذي يتم

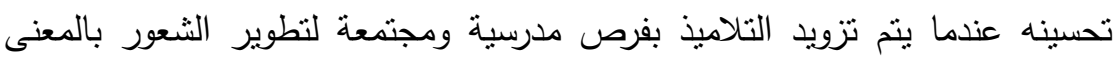

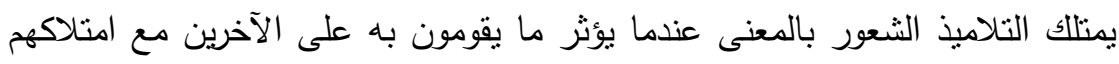

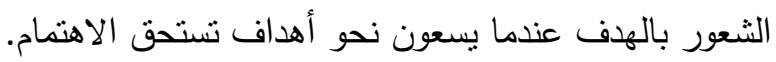

لقد بدأ اهتمام علماء النفس بالخبرة الذاتية الإيجابية والسمات الثخصية الإيجابية

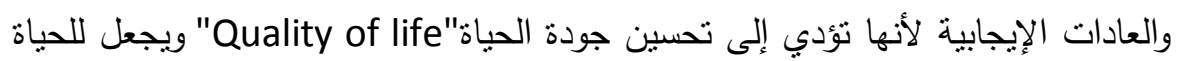

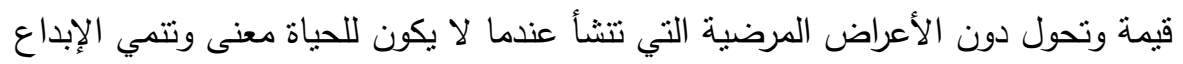

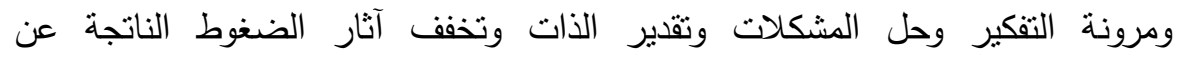
الاضطرابات العضوية والنفسية وتسهل التقدم واكتساب المعارف وتوسع بؤرة اهتمامه

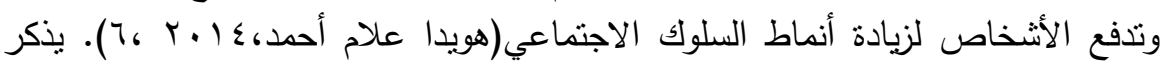




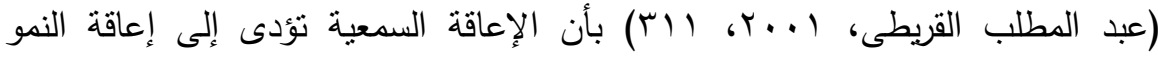

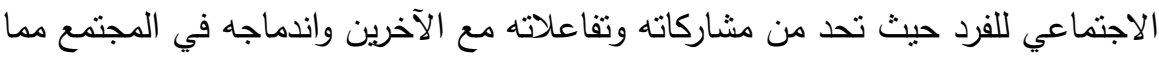

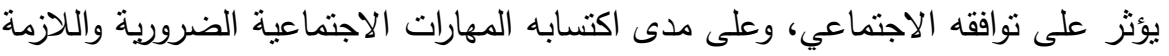

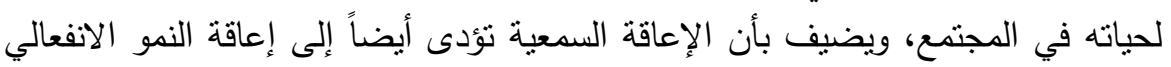
والعاطفي له، ويشير (Paul \& Jackson, (99,9) أن من أهم آنار الإعاقة السمعية

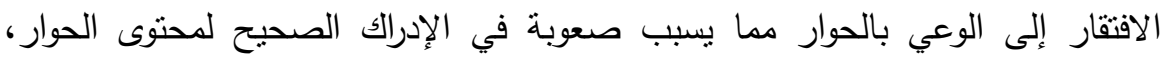
فيعانى الطفل من صعوبة في منابعة الحوار السريع مع أقرانه مما يؤثر سلباً على التنشئة الاجنماعية ومفهوم الذات.

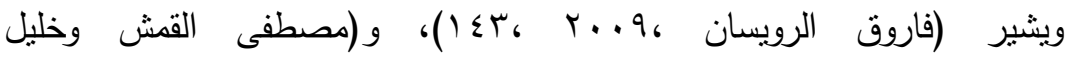

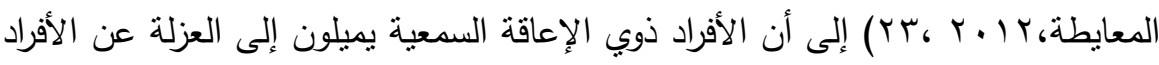

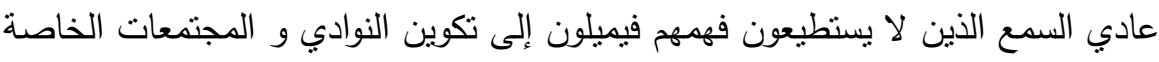
بهم بسبب تعرض الكثير منهم لمواقف الإحباط الناتجة عن تفاعلهم الاجتماعي مع الأفراد عاديي السمع. ويؤكد (شاكر قنديل، 1990 ، بـ) على أنه تكاد تجمع الأبحاث والدراسات

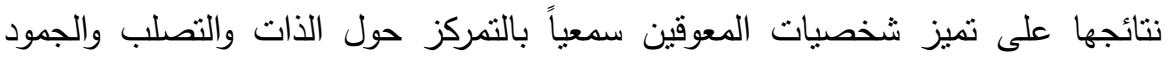
وعدم النضج الانفعالي.

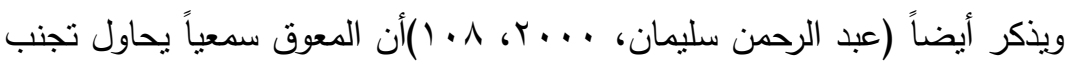

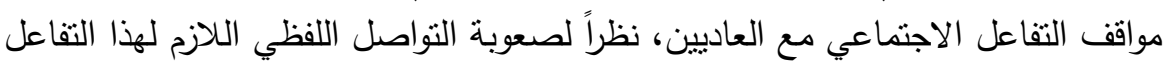

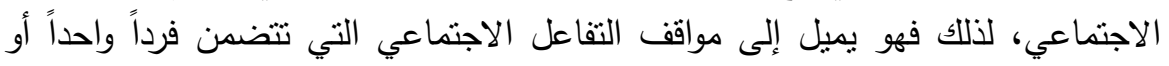
فردين، وذللك لآن كثرة الأفراد تجعله لا يستطيع التركيز مع حركاتهم وإيماءاتهم ونطق

حروفهم.

\section{"Positive Teenage مدخل تنمية الحياة الايجابية للمراهقين -}

\section{-:Development"}

"Positive Teenage يركز مدخل تتمية الحياة الايجابية للمراهقين

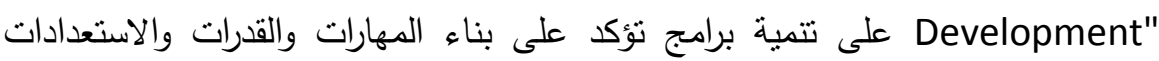

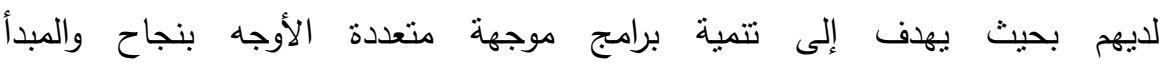

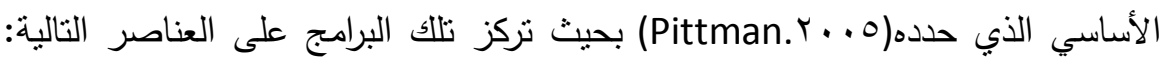

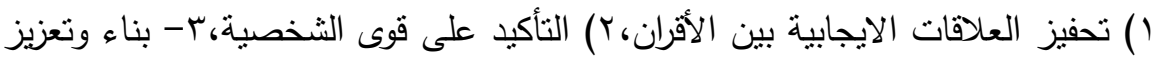

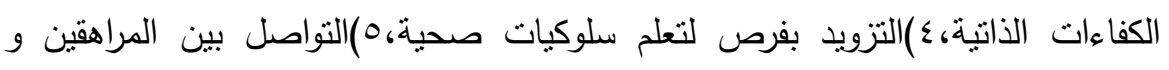

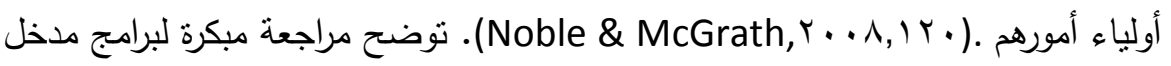
تتمية الحياة الايجابية للمراهقين بأنه من أكثر البرامج فعالية بحيث يستهدف العاء العديد من

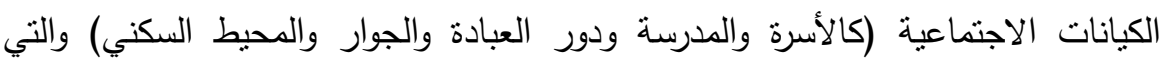


(Catalano et تسعى نحو تعزيز الكفايات الاجتماعية والانفعالية والمعرفية والسلوكية) al, (1999).

يكمن المكون الجوهري لمدخل تتمية الحياة الايجابية للمراهقين (PTD) في الانتقال

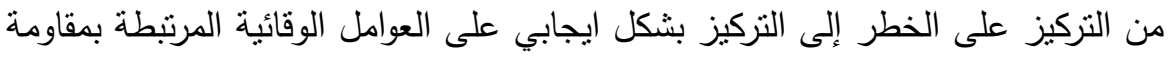

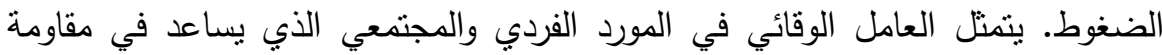

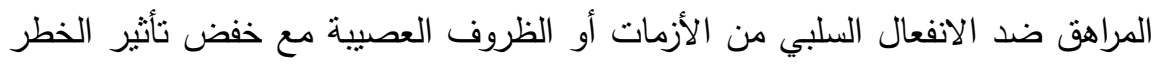

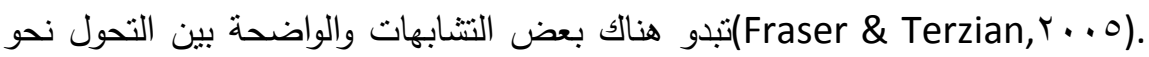

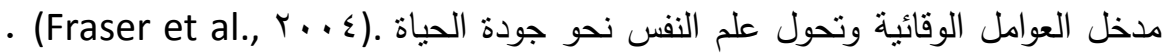

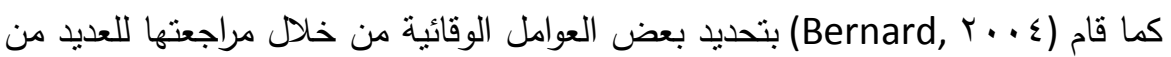

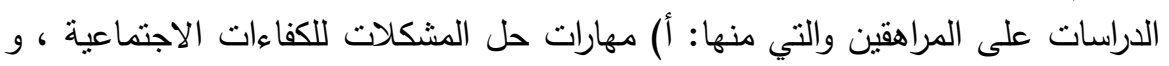

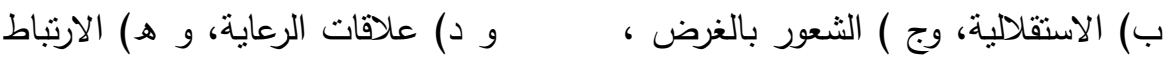
بالمدرسة، وأخيراً و) المشاركة والمساهمة والتوقعات التربوية والأخلاقية المرتفعة.

\section{- الأساليب والاستراتيجيات العلاجية للسيكولوجية الايجابية :-}

على الرغم من شيوع تطبيق العديد من التخخلات العلاجية تحت المدخل العلاجي

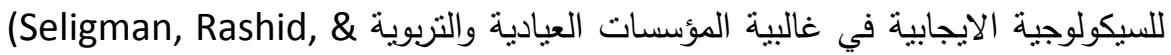

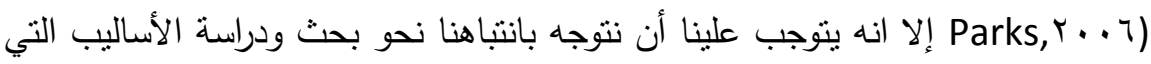

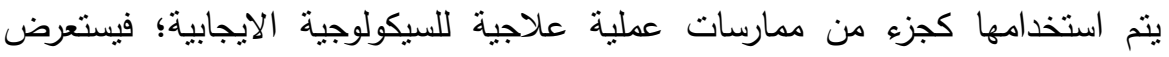
الباحث إمكانية تطبيق الفنيات والاستراتيجيات العلاجية والإرشادية للسيكولوجية الايجابية بغرض لتحسين ممارسات الاختصاصيين النفسيين العاملين في المدارس المصرية حيث

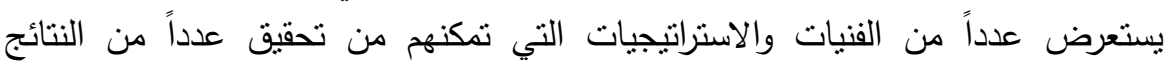
الواقعية داخل المجتمع المدرسي. في اعتقاد الباحث أن الأساليب العلاجية للسيكولوجية

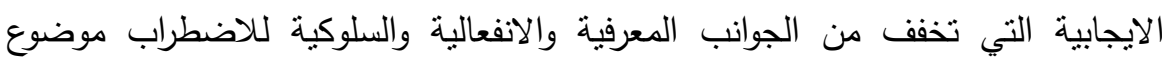

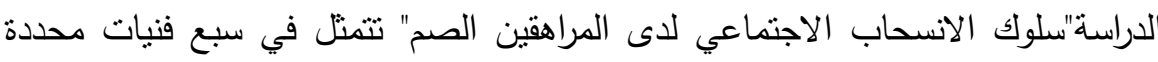

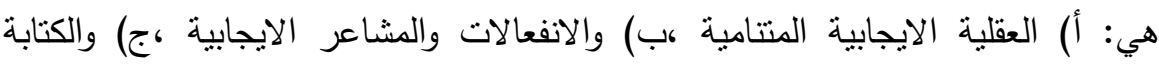

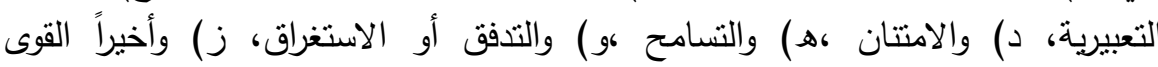
الشخصية.

\section{- خصائص الصم "اللغوية، المعرفية، الجسمية، الاجتماعية الانفعالية": -}

يترك الصمم على أصحابه تأثثراً مباشراً وبالغاً في مجالات النمو المختلفة ومنها النمو اللغوي، نمو القدرات العقلية، النمو الجسمي والحركي، والنمو الاجتماعي الانفعالي وولا ريب أن خصائص الطلاب الصم تختلف عن خصائص الأسوباء فقد أكدت دراسة. (أحلام رجب،r +.r) عدداً من الخصائص التي يمكن إيجازها في:( ) صعوبة إقامة 
علاقات اجتماعية مع الأقران العاديين، ب) الميل إلى الانطواء والانسحاب، وعدم التكيف

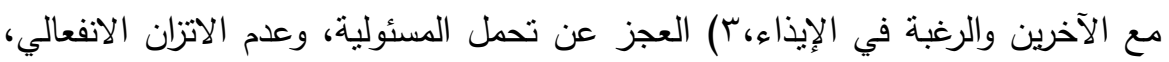
والسلوك العدواني تجاه الآخرين والسرقة، ؟) الا توجد فروق بينهم، وبين التلاميذ العاديين في نفس المرحلة السنية في الذكاء،ه ) سرعة النسيان، وعدم القدرة على ربط الموضوعات الدراسية مع بعضها البعض، ج) الميل إلى الارتفاع في مستوى النشاط بالنسبة لأقرانه العاديين.

- أساليب التواصل لاى المراهقين الصم:يمكن التواصل مع المراهقين الصم من عدة طرق مختلفة هي: (1) طريقة التدريب

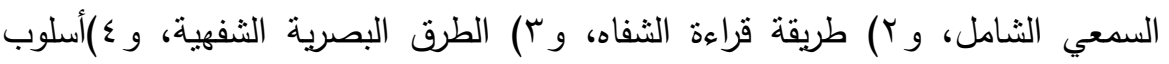

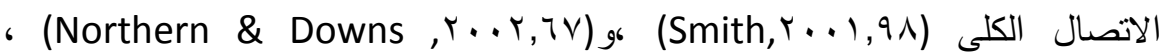

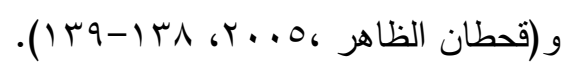

• أدوات الدراسة وخطوات إعدادها وتطبيقها:

1- استمارة جمع البيانات الثخصية والاجتماعية للطالب الأصم كلياً (إعداد الباحث). r- مقياس سلوك الانسحاب الاجتماعي للمراهق الأصم (إعداد الباحث). r- البرنامج العلاجي القائم على الفنيات العلاجية للسيكولوجية الايجابية(إعداد الباحث) أولاً: استمارة جمع البيانات الشخصية والاجتماعية للمراهق الأصم كلياً (إعداد

$$
\text { (البإث:) }
$$

قام الباحث بالاطلاع على العديد من استمارات البيانات المختلفة وذلك لصياغة محتويات هذه الاستمارة، ولقد تم الاعتماد على هذه الاسنمارة بغرض جمع البيانات

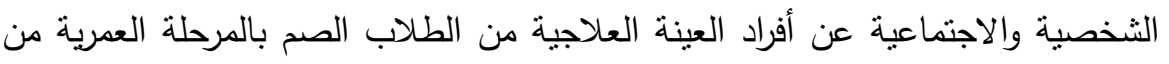

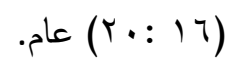

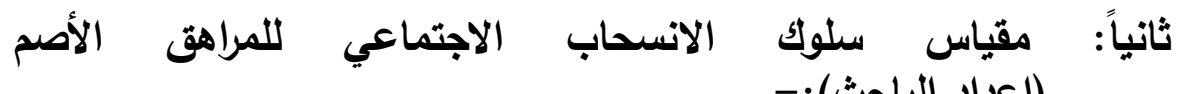
(إعداد الباحث): معند)

تضمن المقياس ثلاثة أبعاد أساسية، هي: () البُّدد المعرفي،و ب) البُّعد الانفعالي،

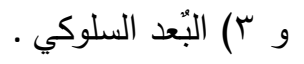

أ- صدق المقياس"Validity": 
تم عرض المقياس في صورته الأولية على لجنة من السادة المحكمين تضم ثلاثة

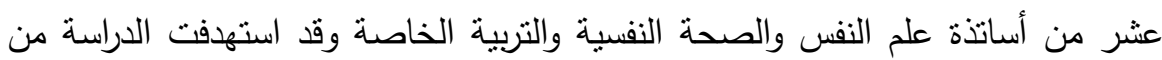
هذا الإجراء الوقوف على مدى وضوح صياغة كل عبارة من عبارات المقياس، ومدى

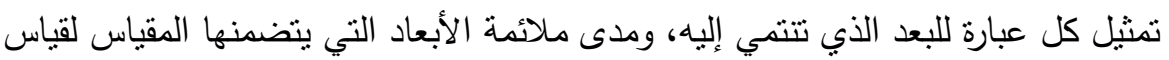

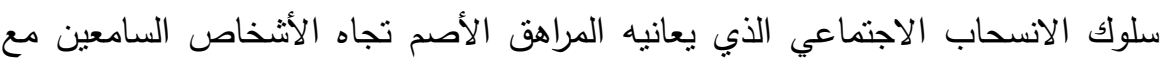

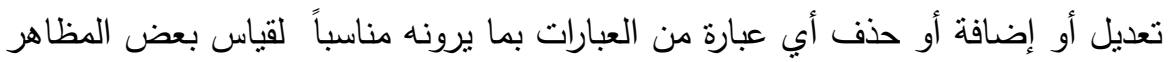

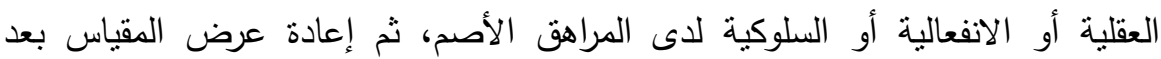

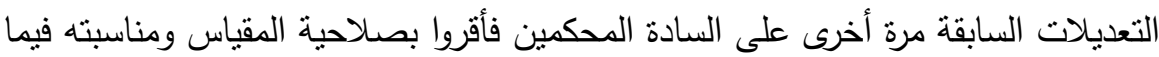

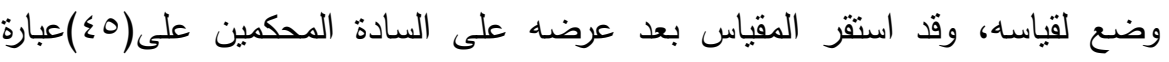
موزعة على الثلاثة أبعاد الرئيسية. r)(الصدق التلازمي (الصدق المرتبط بالمحكاث):-

تم حساب درجة الصدق التلازمي للمقياس بحساب معامل الارتباط بين المقياس ككل وبُعد تقدير الذات المجتمعية على مقياس تقدير الذات للمراهت الأصم(إعداد/ إيمان

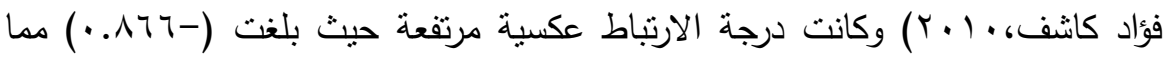
يؤكد على مصداقية المقياس .

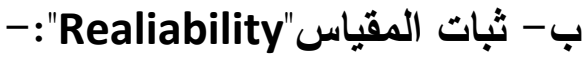

للتأكد من مدى استقرار المقياس وثباته اعتمد الباحث على طريقة "بيرسون" بإعادة

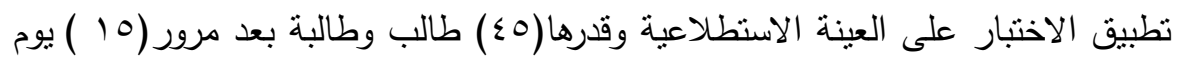

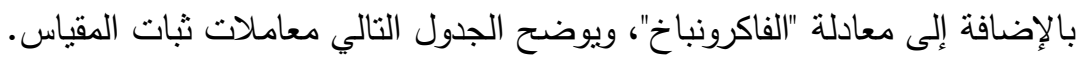

\begin{tabular}{|c|c|c|}
\hline الفاكرونباخ & إعادة تطبيق الاختبار & الطريقة \\
\hline$* * . . V 1$ & $* * . .79$ & معامل الثبات \\
\hline
\end{tabular}

ج-الاتساق الاخلي"Internal Consistency":

بعد تطبيق الصورة الأولية للمقياس(0 §) عبارة على العينة الاسنطلاعية وعددها(0 ؛ طالب وطالبة وتصحيحها وتفريغ استجاباتها بحساب معاملات الارتباط بين الدرجة الكلية

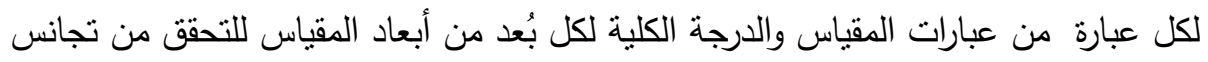
المقياس داخلياً باستخدام طريقة الاتساق الداخلي. يوضح الجدول التالي معاملات الارتباط بين الدرجة الكلية لكل عبارة والدرجة الكلية للبُعد الذي تتنمى إلبه. 
مركز الإرشاد النفسي والتربوي ـ كليت التربيت ـ جامعت سيوط

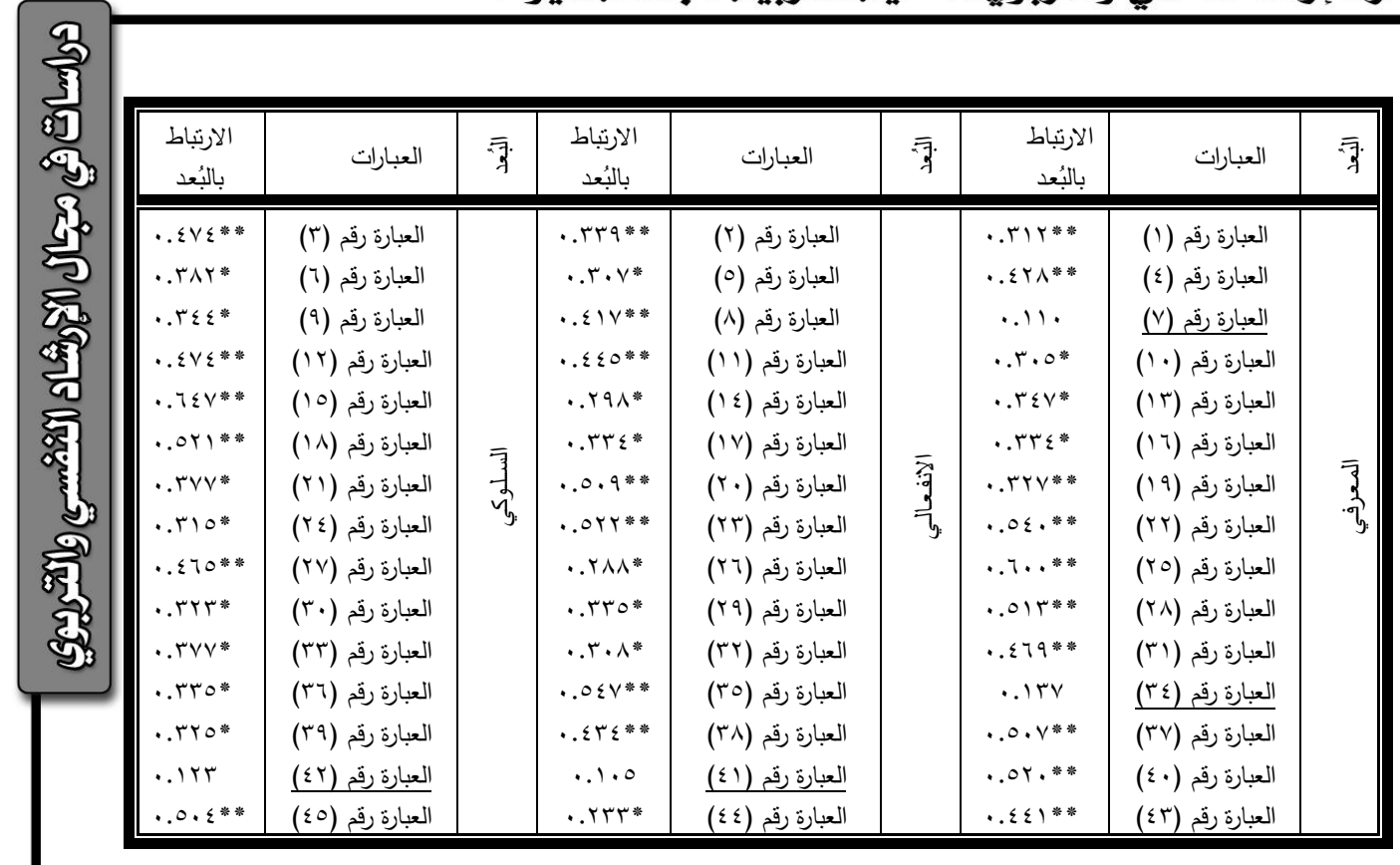

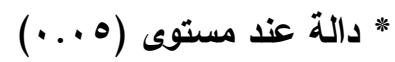

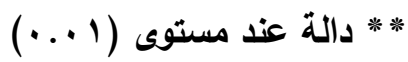

وللتأكيد على تجانس المقياس داخلياً قام الباحث بحساب معاملات الارتباط بين

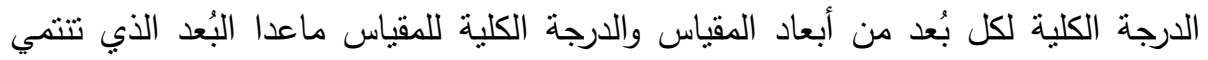
إليه. ويوضح الجدول الثالي معاملات الارتباط بين الدرجة الكلية لكل بُعد والدرجة الكلية

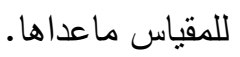

\begin{tabular}{|c|c|c|c|}
\hline السلوكي & الانفعالي & المعرفي & البّعـد \\
\hline $.071 * *$ & $. V \mid r * *$ & $. \vee V \varepsilon . * *$ & الدرجة الكلية \\
\hline
\end{tabular}

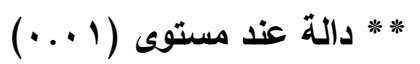

اعتماداً على معاملات الارتباط بين عبارات مقياس سلوك الانسحاب الاجتماعي

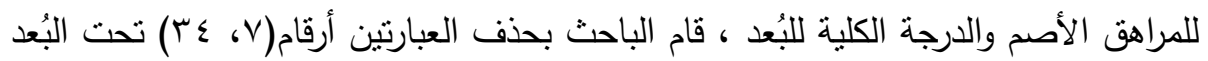

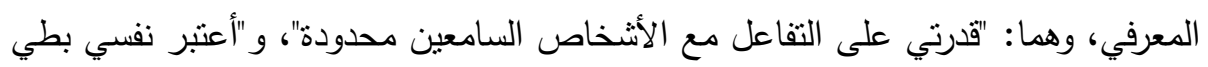

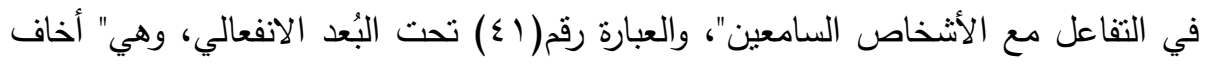

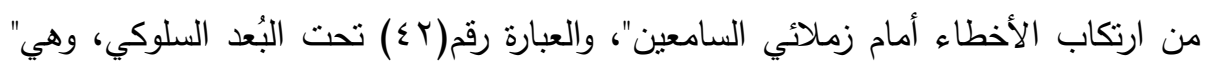

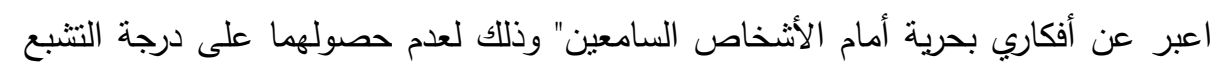


يوضتح الجدول التالي أبعاد الصورة النهائية لمقياس سلوك الانسحاب الاجتماعي للمراهق الأصم، وأرقام عبارات كل بعد.

\begin{tabular}{|c|c|c|c|c|}
\hline \multirow{2}{*}{ الإجمالي } & \multicolumn{2}{|c|}{ عدد العبارات } & \multirow{2}{*}{ عبارات كل بُد } & \multirow{2}{*}{ الأبعاد } \\
\hline & سلبي & ايجابي & & \\
\hline r & 0 & $\wedge$ & $r q-r q-r r-r \cdot-r V-r \varepsilon-r \mid-11-10-1 r-9-\varepsilon-1$ & 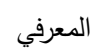 \\
\hline $1 \varepsilon$ & ○ & 9 & $\varepsilon \cdot-r V-r \leqslant-r 1-r \lambda-r 0-r Y-19-17-1 r-1 \cdot-V-0-r$ & 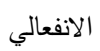 \\
\hline $1 \varepsilon$ & v & v & $\varepsilon 1-r \Delta-r 0-r r-r q-r q-r r-r \cdot-1 V-1 \leqslant-11-\lambda-\tau-r$ & 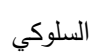 \\
\hline
\end{tabular}

ثالثاً :البرنامج العلاجي القائم على الفنيات العلاجية للسيكولوجية

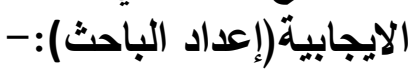
أ- تعريف البرنامج العلاجي (موضوع الاراسة):-

هو مجموعة من الفنيات والاستراتيجيات العلاجية القائمة على مدخل سيكولوجية الحياة الايجابية والمدخل العلاجي المعرفي السلوكي مع أساليب الدعم الايجابي للسلوك ملكئك التي يتم تتفيذها من قبل المعالج أو الأخصائي النفسي سواء داخل المدرسة أو خارجها والهادفة إلى علاج أو على الأقل خفض سلوكيات الانسحاب الاجتماعي اللاتوافقية الغير مقبولة تجاه الأفراد السامعين مع تتمية بعض المهارات والقدرات والإمكانيات الوقائية عن الوني طريق استبدال وتعويض تلك السلوكيات المرضية بسلوكيات بديلة أكثر توافقية والتي ينقص نواجدها لدى أفراد المجموعة العلاجية(المراهقين الصم من ذوي سلوك الانسحاب

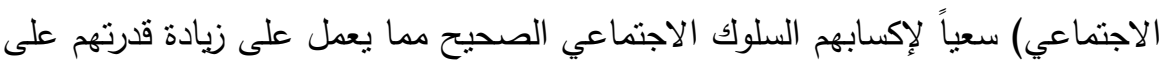

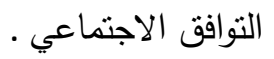

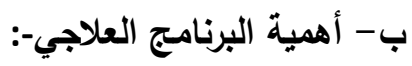

يؤكد الباحث أن تركيز البرنامج المقترح لا يختص بما الذي يعانيه المراهق الأصم

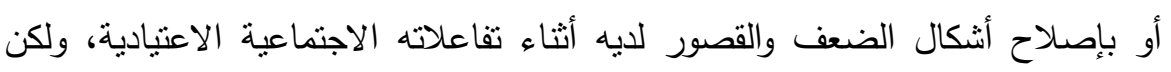
يركز بشكل أساسي وجوهري على صقل وتدعيم نقاط قواه الثخصية الاجتماعية وبصورة

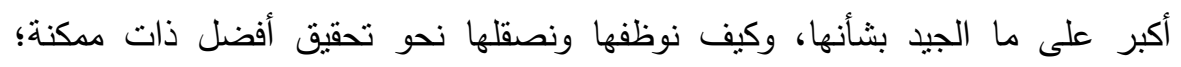

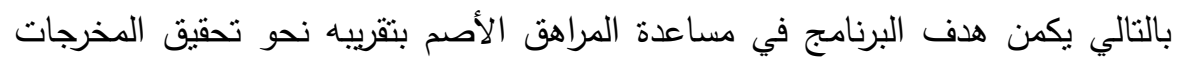
المأمول تحقيقها. 
يتم تطبيق البرنامج على مجموعة واحدة من المراهقين الصم(مجموعة تجريبية

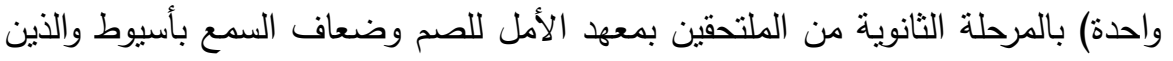

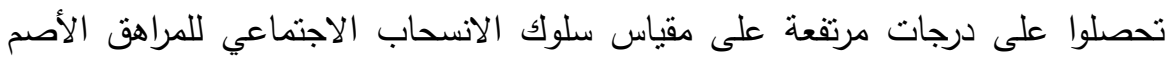

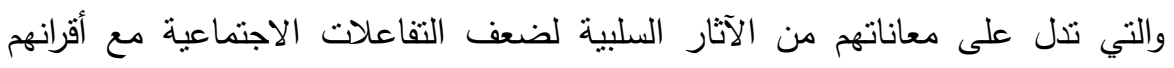

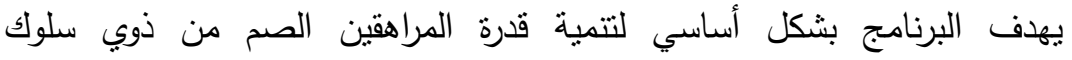

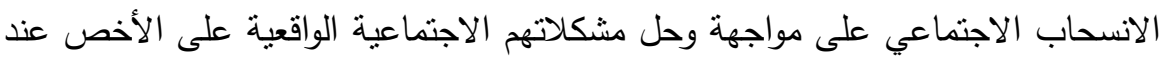

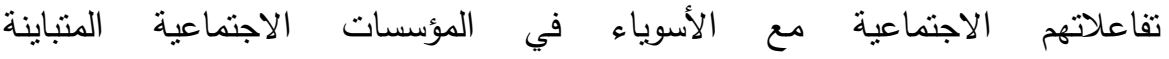

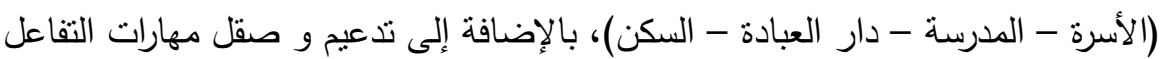

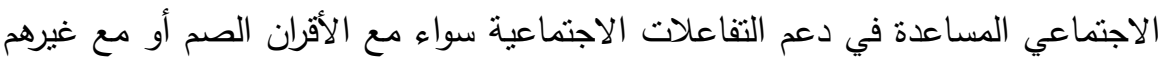
من السامعين اعتماداً على أساليب الدعم الايجابي للسلوك.

$$
\text { هـ - الأساليب المستخدمة في البرنامج-: }
$$

اعتمد الباحث في بناء البرنامج على العديد من فنيات واستراتيجيات المدخل

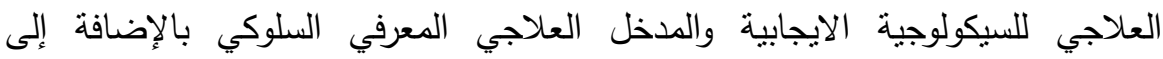

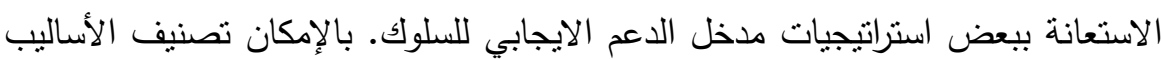
والاستراتيجيات المستخدمة في البرنامج لتقع تحت ثلاثة مجالات أساسية: معرفية، وانفعالية، وسلوكية.

-

يتم من خلالها التعامل مع الأفكار والمعتقدات الخاطئة اللاتوافقية الخاصة باضطراب سلوك الانسحاب الاجتماعي لكل فرد من أفراد المجموعة العلاجية مع القيام بتعديلها أو دحضها عن طريق تتمية المعلومات والمعارف السليمة التوافقية لديهر - أساليب واستراتيجيات (نفعالية: 
وهى تعنى بمساعدة أفراد العينة العلاجية على ممارسة التفكير العقلي واستخدام العقل والمنطق في الحكم على الأمور وإكسابهم خبرات جديدة تقوم على علاقات اجتماعية سليمة عن طريق أساليب للتعامل مع مشاعر الخوف والقلق والحرمان بسبب الإعاقة وتتمية مشاعر الود والمحبة والتعاون بينهم وبين السامعين سواء من أقرانهم ممن هم في نفس أعمارهم أو ممن يكبرونهم أو يصغرونهم. - أساليب و استراتيجيات سلوكية: وتعني بمساعدة أفراد المجموعة العلاجية على اكتساب السلوكيات والتصرفات التوافقية البديلة عوضاً عن السلوكيات الانسحابية اللاتوافقية. و - محتويات البرنامج-:

أثتمل البرنامج العلاجي موضوع الدراسة على(Y^) جلسة علاجية استغرق تتفيذ

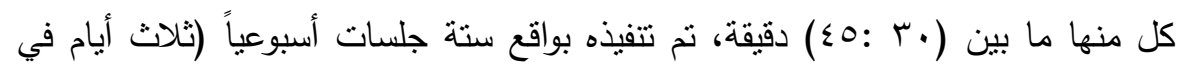
الأسبوع) بواقع جلستين في كل يوم يتخلاها استراحة لمدة خمسة دقائق. يقوم البرنامج على استخدام فنيات واستراتيجيات سيكولوجية الحياة الايجابية، والعلاج المعرفي السلوكي، بالإضافة إلى بعض أساليب دعم السلوك الايجابي للتخلص من سلوك الانسحاب

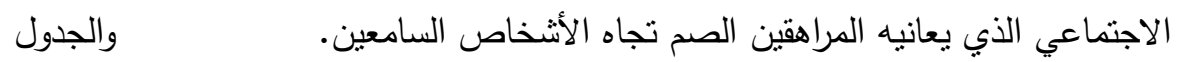
التالي يوضح عناوين جلسات البرنامج العلاجي بالمجال العلاجي الذي تختص به.

\begin{tabular}{|c|c|c|c|c|c|}
\hline المجال & عنوان الجلسة & م & | المجال & عنوان الجلسة & 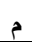 \\
\hline \multirow{5}{*}{$\begin{array}{l}\overline{3} \\
\text { नु } \\
\frac{1}{?} \\
\overline{3} \\
\overline{3}\end{array}$} & فنية"التسامح" & 10 & \multirow{8}{*}{ नें } & تمهيد وتعارف & 1 \\
\hline & فنية "الامتتان" & 17 & & مقدمة ايجابية & r \\
\hline & قيم "التفكير الإبتكاري"و"المبادرات الايجابية" & IV & & مراجعة القصص الايجابية & $r$ \\
\hline & قيم "السعادة" "الحب" & 11 & & الايجعايية بمفهوم سيكولوجية الحياة & $\varepsilon$ \\
\hline & قيم "الثقة بالذات" و "التقرد البشري" & 19 & & تقديم الأسس النظرية لمدخل سيكولوجية & 0 \\
\hline \multirow{3}{*}{ 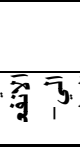 } & جلسة متابعة & r. & & تقديم فنيات مدخل سيكولوجية الحياة & 7 \\
\hline & التعلم والكفاءة الانفعالية ومهاراتهما & Y) & & نقاط القوة الشخصية الاجتماعية & $\mathrm{v}$ \\
\hline & الكفاءة الاجتماعية ومهاراتها & rr & & تتمية نقاط القوة مع صقل الانفعالات & $\wedge$ \\
\hline
\end{tabular}


مركز الإرشاد النفسي والتربوي ـ كليت التربيت ـ جامعت سيوط

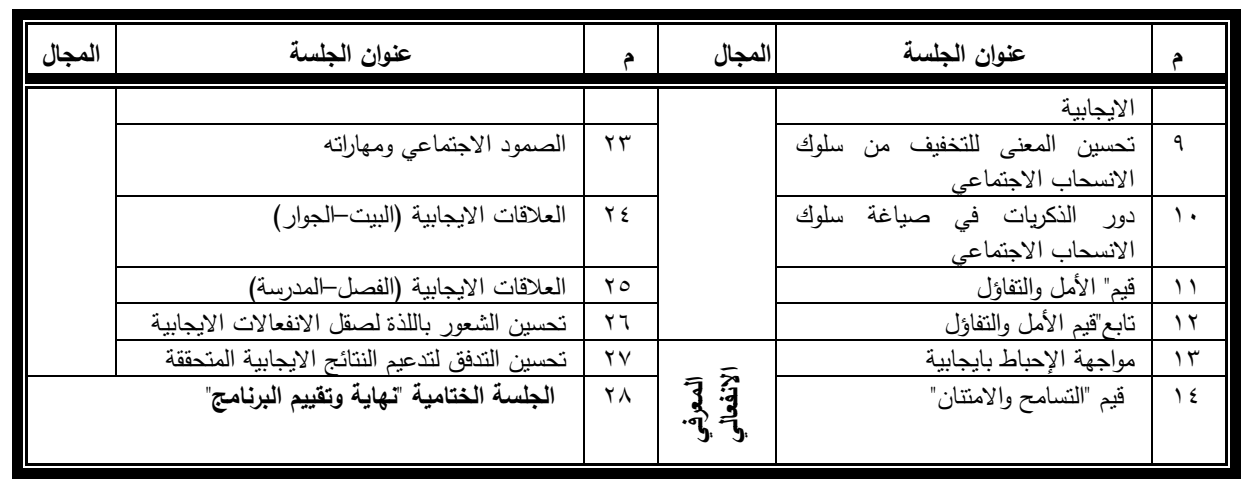

$$
\text { • أنتائج الدراسة::- }
$$

أ- نتيجة الفرض الأول وينص على:

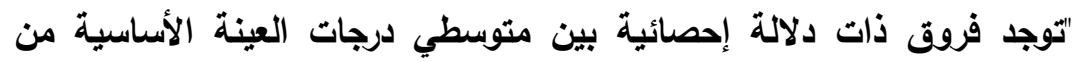

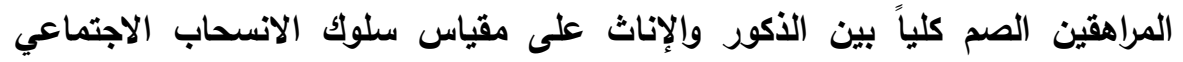

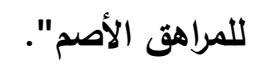

وللتحقق من صحة هذا الفرض قام الباحث بنطبيق مقياس سلوك الانسحاب

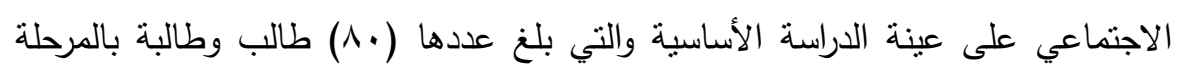

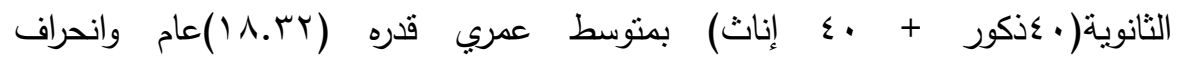

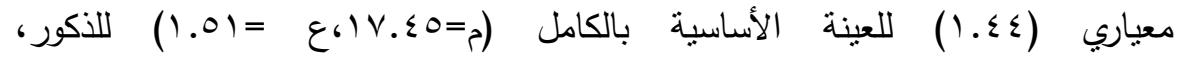

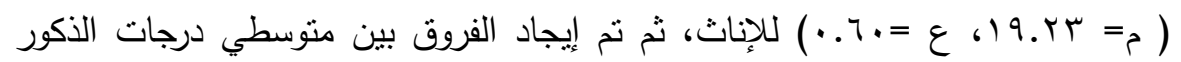

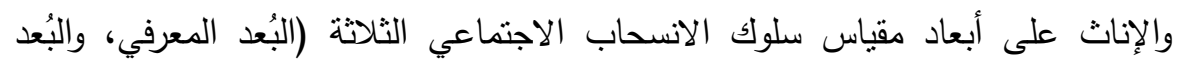

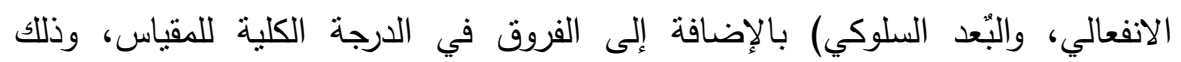

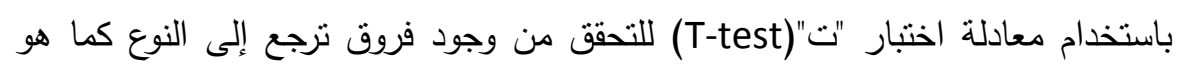
واضح في الجدول التالي.

\begin{tabular}{|c|c|c|c|c|c|c|}
\hline \multirow{2}{*}{ | الدلالة } & \multirow{2}{*}{ ق قيمة "ت" } & \multicolumn{2}{|c|}{ الإناث (ن = • ع ) } & \multicolumn{2}{|c|}{ الذكور (ن = •ـ ) } & \multirow{2}{*}{ أبعاد المقياس النوع } \\
\hline & & $\varepsilon$ & 5 & $\varepsilon$ & r & \\
\hline د الة & 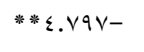 & r.9TE & rq.ro. & r.క17 & r..10. & البُعد المعرفي \\
\hline 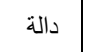 & **T.Y T & r. 199 & rی. 90. & r.STr & rV.ITO & البُعد الانفعالي \\
\hline |غير دالة & $\cdots \wedge 1$ & $r .979$ & rA. $\leqslant 0$. & r.TVq & rA.०.. & البُعد السلوكي \\
\hline دالة ل & $* * 1 r . \leq 79-$ & צמון & 1..70. & r.TV. & NI.VVO & الدرجة الكلية للمقياس \\
\hline
\end{tabular}




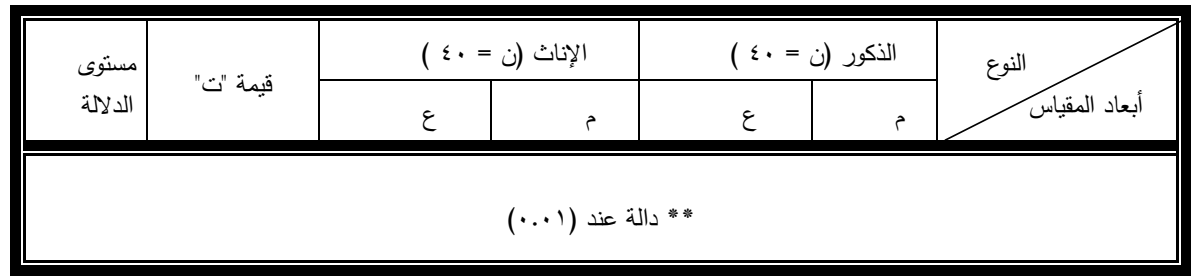

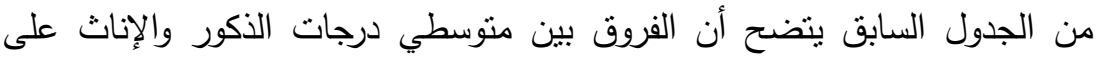

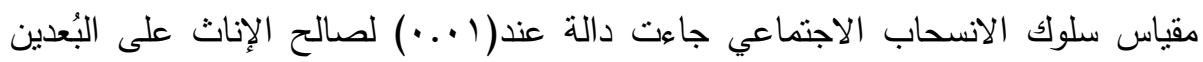

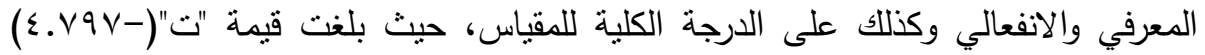

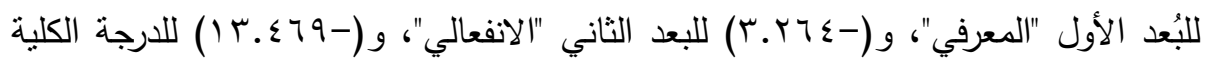

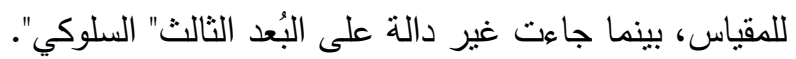

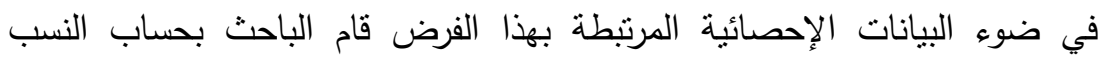

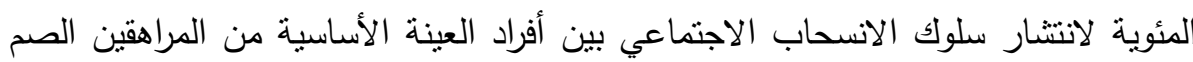

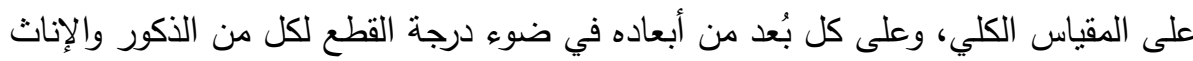
كل على حده ، كما في الجدول التالي.

\begin{tabular}{|c|c|c|c|c|c|c|}
\hline \multicolumn{2}{|c|}{ 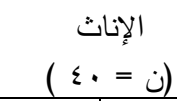 } & \multicolumn{2}{|c|}{ 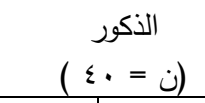 } & \multicolumn{2}{|c|}{ 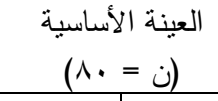 } & \\
\hline$\%$ & ن ن & $\%$ & ن & $\%$ & ن & \\
\hline 1 1 .0 & 0 & $1 V .0$ & v & 10 & ir & البُعد المعرفي \\
\hline 18.0 & V & ro & 1. & ri.ro & iv & البُعد الانفعالي \\
\hline 10 & 7 & 1. & $\varepsilon$ & 17.50 & r & البُعد السلوكي \\
\hline ס. & 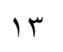 & r.o & 9 & ru.ro & YI & الدرجة الكلية للمقياس \\
\hline
\end{tabular}

لقد تبين لاى الباحث أن عدد الطلاب الصم الذين يعانون من سلوك الانسحاب

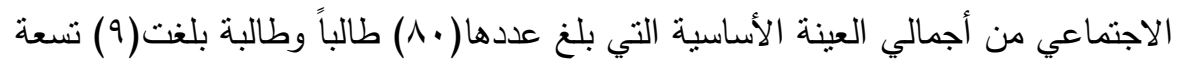

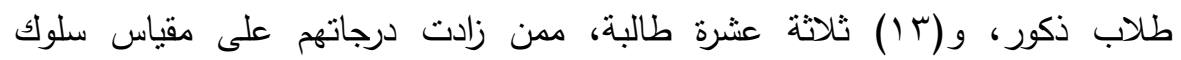

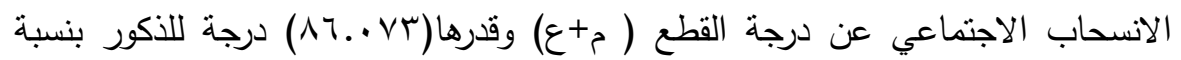

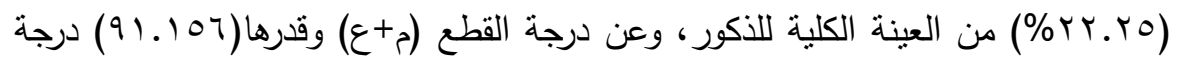

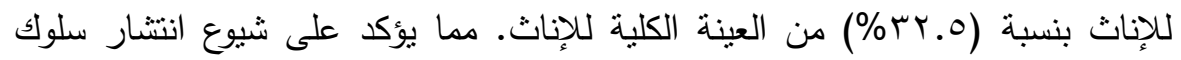

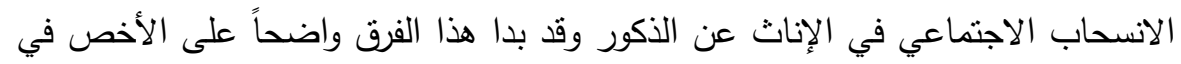

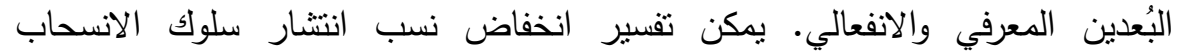

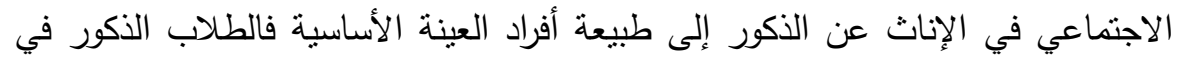

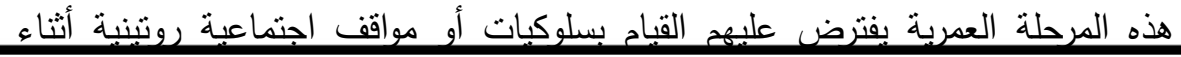


تعاملاتهم مع الآخرين سواء داخل المدرسة أو خارجها على عكس الإناث من ذوي

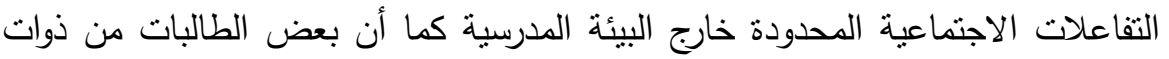
الإقامة الداخلية بالإضافة إلى الطبيعة المجتمعية التي تفرض على الذكر القيام بمتطلبات معيشية وأعمال مهنية يعتقد أن من غير الواجب القيام بها أو تكليفها للإناث. ب- نتيجة الفرض الثاني وينص على: " يوجد فرق ذو دلالة إحصائية بين متوسطي رتب درجات العينة العلاجية في القياسين القبلي والبعدي على مقياس سلوك الانسحاب الاجتماعي للمراهث الأصم لصالح القياس القبلي".

وللتحقق من صحة هذا الفرض قام الباحث بتطبيق مقياس سلوك الانسحاب الاجتماعي للمراهق الأصم على عينة الدراسة العلاجية قبل وبعد تتفيذ البرنامج العلاجي والتي بلغ عددها (9) طلاب ثم نم إيجاد الفروق بين رثب درجات أفراد العينة التجريبية في

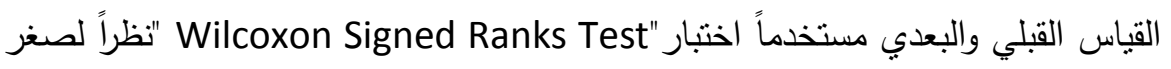
حجم العينة بغرض التحقق من وجود فروق حقيقية بين رتب درجات أفراد المجموعة

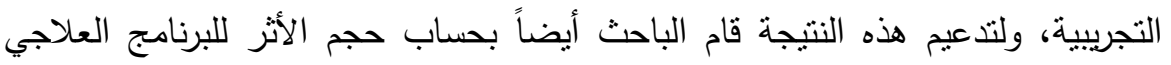

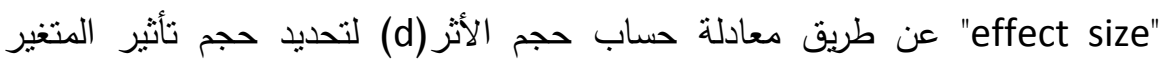
المستقل(البرنامج العلاجي) على المتغير التابع (سلوك الانسحاب الاجتماعي) باستخدام المعادلة: - n

Z

$d=$

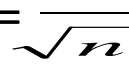

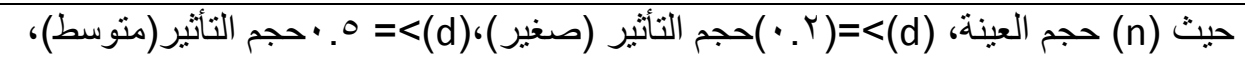
) > (d)

ويوضتح الجدول التالي دلالة الفروق بين متوسطات رتب درجات العينة العلاجية في القياسين القبلي والبعدي على مقياس سلوك الانسحاب الاجتماعي للمراهق الأصم

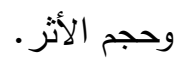


مركز الإرشاد النفسي والتربوي ـ كليت التربيتة ـ جامعت سيوط

\begin{tabular}{|c|c|c|c|c|c|c|c|c|c|}
\hline \multirow[t]{2}{*}{ الأثر } & \multirow{2}{*}{ قيمة } & \multirow{2}{*}{ مستوى الدلالة } & \multirow{2}{*}{ قيمة } & \multicolumn{2}{|c|}{ مجموع الرتب } & \multicolumn{2}{|c|}{ منوسط الرتب } & \multirow{2}{*}{ القياس } & \multirow{2}{*}{ الأبعاد } \\
\hline & & & & الإيجابية & السلبية & الإيجابية & السلبية & & \\
\hline \multirow[b]{2}{*}{ كبير } & \multirow{2}{*}{$. . \wedge 91-$} & \multirow{2}{*}{ 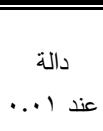 } & \multirow{2}{*}{ T.TVT- } & \multirow[b]{2}{*}{ صفر } & \multirow{2}{*}{$\leq 0 .}$. & \multirow[b]{2}{*}{ صفر } & \multirow{2}{*}{$0 .}$. & ق & \multirow{2}{*}{ البُعد المعرفي } \\
\hline & & & & & & & & ب & \\
\hline \multirow{2}{*}{ كبير } & \multirow{2}{*}{$. .19 \%-$} & \multirow{2}{*}{ عند ال... } & \multirow{2}{*}{ r.TA.- } & \multirow{2}{*}{ صفر } & \multirow{2}{*}{$\leq 0 \ldots$} & \multirow{2}{*}{ صفر } & \multirow{2}{*}{$0 . .}$. & ق & \multirow{2}{*}{ البُعد الانفعالي } \\
\hline & & & & & & & & ب & \\
\hline \multirow{2}{*}{ كبير } & \multirow{2}{*}{$. .19 .-$} & \multirow{2}{*}{ عند ال ... } & \multirow{2}{*}{ r.TV.- } & \multirow{2}{*}{ صفر } & \multirow{2}{*}{$\leq 0 . .}$. & \multirow{2}{*}{ صفر } & \multirow{2}{*}{$0 . .}$. & ق & \multirow{2}{*}{ البُعد السلوكي } \\
\hline & & & & & & & & ب & \\
\hline \multirow[b]{2}{*}{ كبير } & \multirow{2}{*}{$. .190-$} & \multirow{2}{*}{ 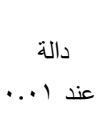 } & \multirow{2}{*}{ Y.TAะ- } & & & & & ق & \\
\hline & & & & صفر & $\leq 0 . \ldots$ & صفر & $0 .$. & ب & الدرجة الكلية \\
\hline
\end{tabular}

يتضح من الجدول السابق أن قيمة (Z) جاءت دالة بين القياسين القبلي والبعدي

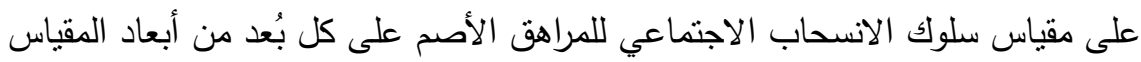

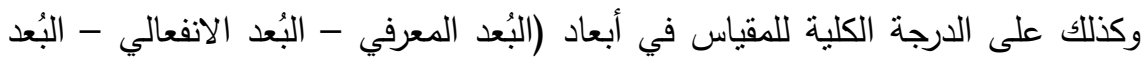

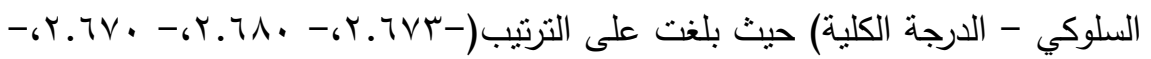

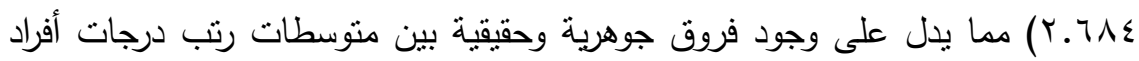

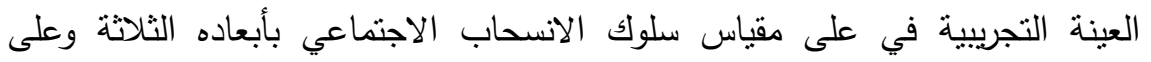

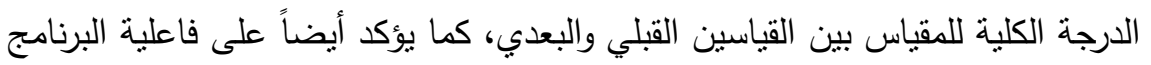

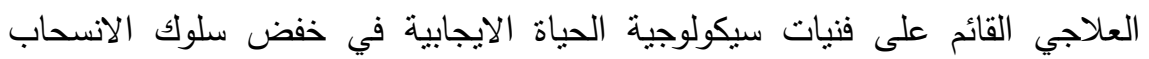
الاجتماعي لدى أفراد العينة العلاجية.

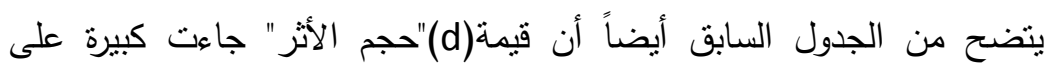

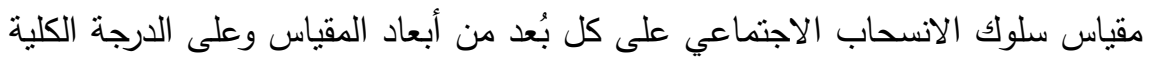

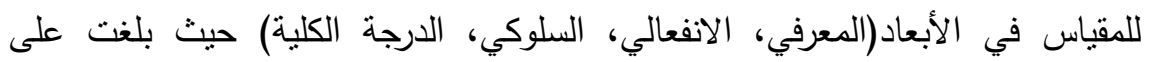

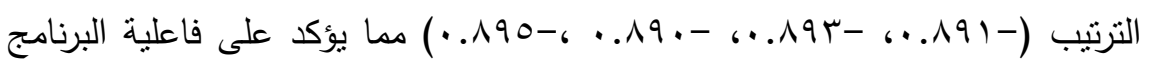

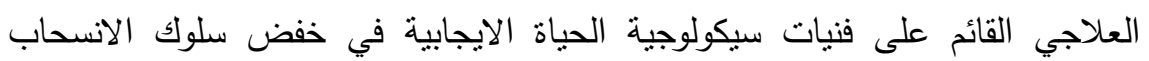
الاجتماعي لدى أفراد العينة العلاجية.

$$
\text { • أ- مراجع الدراسة: - }
$$




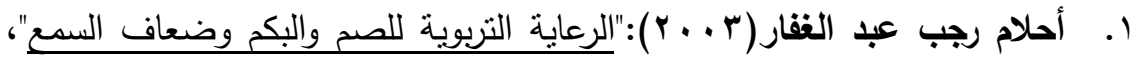
دار الفجر للنشر، القاهرة(مصر ).

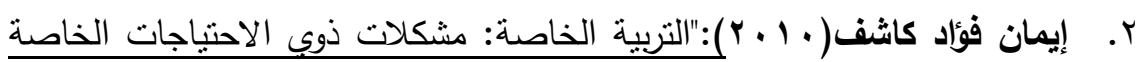

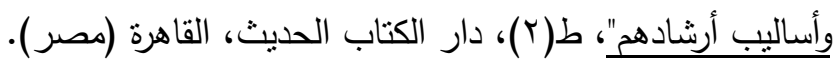

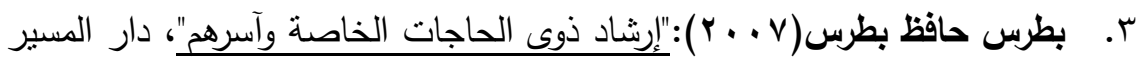
للنشر والتوزيع ،عمان.

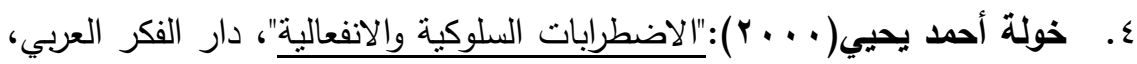

$$
\text { عمان(الاردن). }
$$

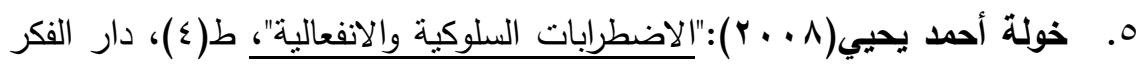

$$
\text { العربي، عمان (الأردن) : الاضطرابات }
$$

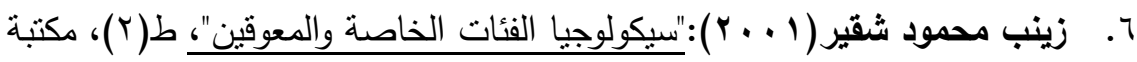
النهضة المصرية، القاهرة (مصر).

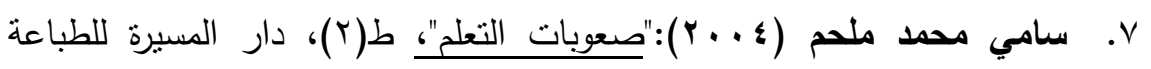

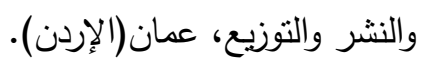

1. شاكر قنديل(900 199):"سيكولوجية الطفل الاصم و منطلبات إرشاده ،المؤتمر

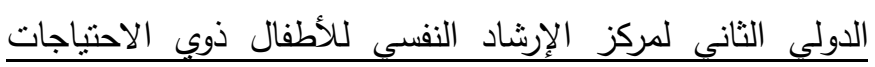

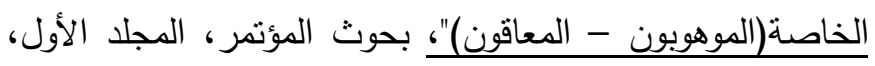

$$
\text { جامعة عين شمس، القاهرة (مصر) . }
$$

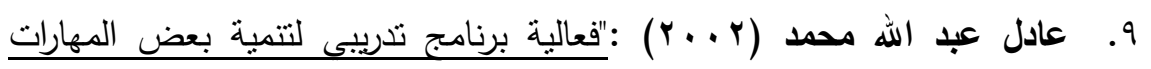

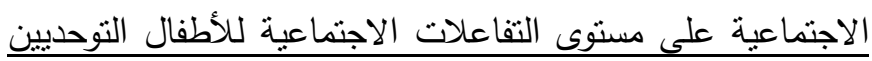

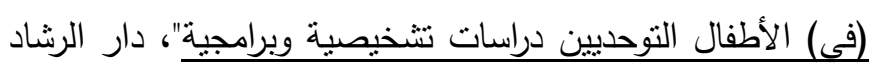

$$
\text { للطبع والتوزيع، القاهرة(مصر ). }
$$

• (. عبد الرحمن سيد سليمان ( . . r):"سيكولوجية ذوب الاحتياجات الخاصة(الدفهوم

$$
\text { ووالفئات)"، الجزء الأول، مكتبة زهراء الثرقئل (القاهرة). }
$$

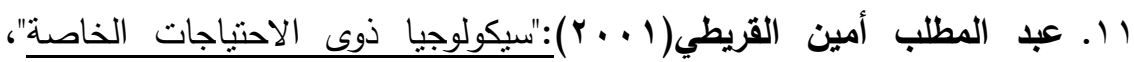

$$
\text { ط(ب)، دار الفكر العربي، القاهرة (مصر). }
$$




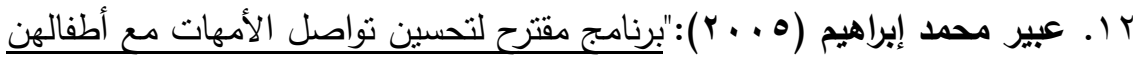

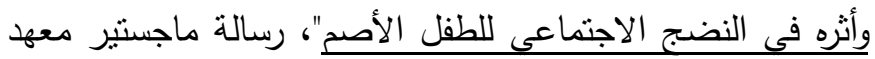

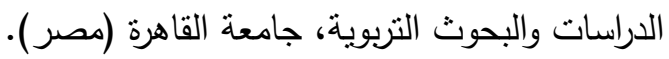

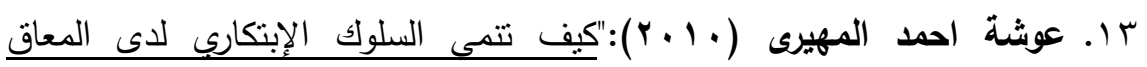

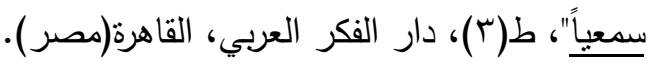

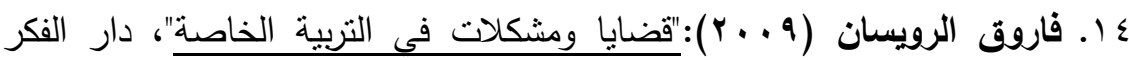
للطبع والنشر ،عمان (الأردن).

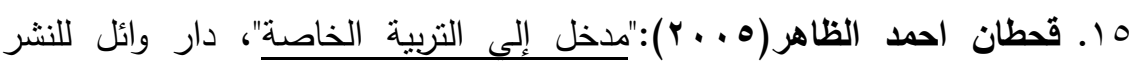
والتوزيع، عمان(الأردن).

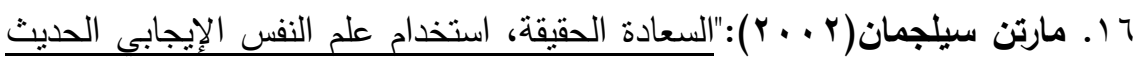

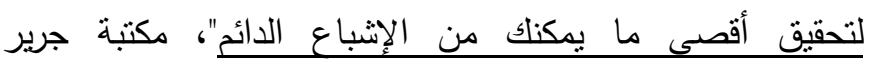
،الرياض(المملكة العربية السعودية).

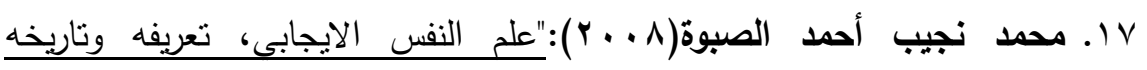

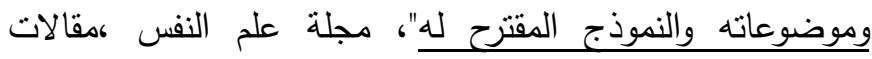

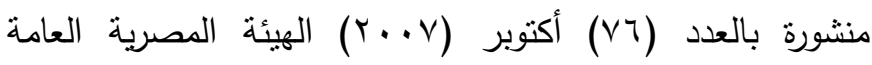
للكتاب، القاهرة(مصر) ).

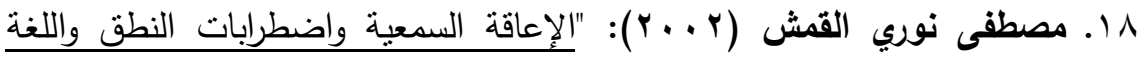

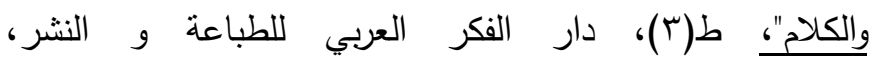

$$
\text { عمان(الأردن). }
$$

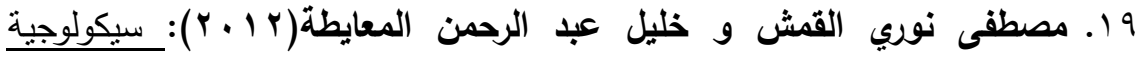

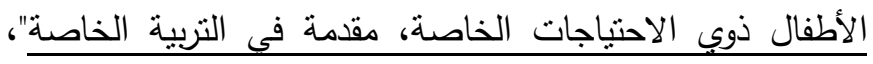

ط(0) ، دار المسيرة للنشر والتوزيع والطباعة، عمان (الأردن).

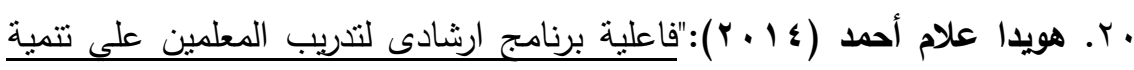

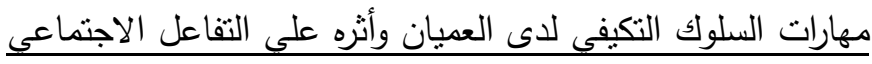

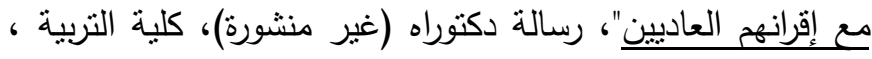
جامعة أسيوط(مصر ).

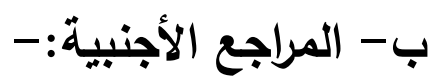

1.Catalano, R.F., Berglund, M.L., Ryan, J.A., Lonczak, H.S. \&

Hawkins, J.D. (1999): "Positive youth development 
in the United States: Research findings on evaluations of positive youth development programs". Seattle, Washington: Social Development Research Group, University of Washington.

r. Clonan, S.M., Chafouleas, S.M., McDougal, J.L., \& Riley-Tillman, T.C. (r. . s):"Positive psychology goes to school: Are we there yet? Psychology in the Schools", Vol. s), Issue (1), pages (1.1-11.).

r. Fraser, M.W., \& Terzian, M.A. ( r . . o):"Risk and resilience in child development: Practice principles and strategies. In G.P. Mallon \& P. McCartt Hess (Eds.), Handbook of children, youth and family services: Practices, policies and programs, Columbia University Press, New York(USA).

s. Fraser, M.W., Kirby, L.D., \& Smokowski, P.R. ( r. . క):" Risk and resilience in childhood". In M.W. Fraser (Ed.)," $\underline{\text { Risk }}$ and resilience in childhood", Washington D.C: NASW Press, pages ( 1 r- 7 7).

๑. Lokanadha, R.( r...):"Education of children with special needs", London discovery publishing House, ind edition, page ( $\left({ }^{\prime}\right)$

7. Noble, Toni \& McGrath, Helen ( r. . 1):"The positive educational practices framework: A tool for facilitating the work of educational psychologists in prompting pupil wellbeing, Educational \& child psychology, The British Psychological Society Vol. no,( ro),Issues no.( r), pages (1) 9-1 rz).

V. Northern, J. \&Downs, P.( F . . Y):"Hearing in children Philadelphia ",Lip-Pincott Williams \& Wilkins Publishing Co., Page( $7 \mathrm{~V}$ ) 
A. Paul, P. V, \& Jackson, D .W.( $199 \mathrm{r})$ :"Toward a psychology of deafness : Theoretical and Empirical Perspectives", Allyn and Bacon, Needham Heights, MA(USA), page (9)).

9. Pittman, K., ( r. . Q):"Moving ideas to impact to change the odds for youth: Charting the forum's course to r.1.: The Forum for Youth Investment Impact Strategies", presented at (June $1 \mathrm{r}, \mathrm{r} . \mathrm{.oO})$.

1. Reschly, D.J. \& Ysseldyke, J.E. (19११): Paradigm shift: The past is not the future. In T. Gutkin \& C. Reynolds (Eds.) The handbook of school psychology, ( ${ }^{\mathrm{rd}}$ ed.), New York: Wiley, pages ( $r-r \cdot)$.

11. Reschly, D.J. (r...): The present and future status o school psychology in the United States. School Psychology Review, Vol. ra, pages (0. Korr).

Ir. Seligman, M. E., Rashid, T., \& Parks, A. C. ( r. . ఛ):"Positive psychotherapy", American Psychologist Journal, Vol. no. ( 71$)$, pages ( $V$ V $\leqslant-V \lambda$ ).

1 r. Smith, D. ( . . 1):"Introduction to Special Education: Teaching in an age of challenge", Boston Allyn and Bacon publishing Co., page (91).

1.. Weare, K. \& Gray, G. ( r.. \&):"What works in developing children's emotional and social competence and wellbeing?" Research Brief, Department for Education and Skills, Vol. ( $\leqslant \circ 7)$. 